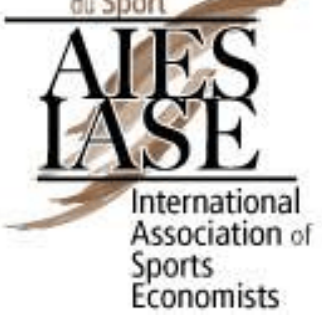

\title{
Market Impact of International Sporting and Cultural Events
}

\author{
António Miguel Martins ${ }^{\dagger}$ and Ana Paula Serra ${ }^{\dagger+}$
}

June 2007

\begin{abstract}
This paper investigates the impact of international sporting and cultural events on national stock markets. We study market reaction to the announcements of the selected country hosting the Summer and Winter Olympic Games, the World Football Cup, the European Football Cup and World and Specialized Exhibitions. We also measure the market effects of the announcement of the nomination of the European Cultural City. First, we evaluate the abnormal returns of winning bidders at (and around) the announcement date using an event study methodology. We study the impact at market and industry-levels. Second, we analyze the determinants of the variation in abnormal returns across events and industries on the basis of a set of variables found important by previous studies and control for the prior probability of observing the event. Third, on the basis of a simple model of partial anticipation, we reexamine the abnormal returns observed for the winning and losing countries and perform a series of tests to disentangle the different theoretical arguments that could account for the observed stock market behavior. Our initial results suggest that the abnormal returns measured at the announcement date and around the event are not consistently different from zero. Further, when we look at particular industries, we find no evidence supporting that industries, that a priori were more likely to extract direct benefits from the event, observe positive significant effects. Yet when we control for the prior expectations, the announcement of these mega-events is associated

${ }^{\dagger}$ Faculdade de Economia da Universidade do Porto

${ }^{+\dagger}$ CEMPRE, Faculdade de Economia da Universidade do Porto, Faculdade de Economia da Universidade do Porto, Rua Dr. Roberto Frias, 4200-464 Porto, Portugal: Tel +35122 557 1255, Fax +35122 550 5050, Email: erra@fep.up.pt
\end{abstract}


with a positive market reaction in the nominated country and a negative reaction in the losing country. Overall we interpret our findings as supportive of rational asset pricing and partial anticipation.

JEL Classification Codes: G31, G14, L83

Keywords: Market efficiency; event studies, mega-events 


\section{Introduction}

This paper investigates the impact of international sporting and cultural events on the stock markets of host countries. These are mega, one-time events entailing large public and private investments.

Why should we observe a market reaction to the announcement of such mega events and of what magnitude? Two main competing arguments predict that these events produce non-negative abnormal returns as of the announcement date.

Assuming that the event was not anticipated, under the null hypothesis of efficient markets, positive or negative abnormal returns would reflect that investors anticipate that this (unexpected) news has a positive/negative valuation effect on the market capitalization of listed firms (Fama, 1965). Assuming managers maximize shareholders' value, only positive NPV projects would be undertaken, and market prices would adjust upwards the event-related news. Further, anticipation of (net) economicwide benefits driven by event-related international exposure, public infrastructure improvements, and multiplier effects of the initial revenues would result in a positive impact for the aggregate market. Variation in abnormal returns across firms (or industries) would reflect the differential net benefit each firm (industry) would extract from the event.

Alternatively, market reaction to winning news could reflect a national positive sentiment caused by pride, self-esteem or joy associated with the fact that the country was chosen to host and sometimes organize an international (most of the times) worldwide broadcasted and recognizably important event. In contrast, the first explanation assumes that investors are rational and predicts that, when sentiment is not associated with any tangible economic effects, this news will produce no effect on market prices.

The market reaction on the day an event is announced may not accurately measure the true economic impact of the events if investors anticipate the event will occur (Malatesta and Thompson, 1985). The magnitude of the effects observed should 
be of smaller magnitude and, the greater the anticipation, the lower the impact as of the announcement date. This is particularly true for the events we study because in most instances the outcome is at least partially anticipated by investors.

Both arguments above predict that winning (losing) countries observe positive (negative) market returns. Rational arguments predict that the effect should be asymmetric for winners and losers and across events, because the perceived economic impact can vary widely across countries. In a different way, behavioral arguments maintain that, if prices are affected by investor sentiment, regardless of the objective probability of observing the event and of the economic impact of the investment, we should observe a market rise in wins and a market decline in losses. Further, the fact that investors extract more pain from bad news than the joy they sense when a good outcome is revealed, can motivate different market reactions for winning and losing countries, and the magnitude of the effect would therefore be greater for losers than for winners. When the event is not anticipated at all, i.e. event-news is a complete surprise, and investors are rational, the impact should be felt only on the winner's market value. In reality this scenario is rather implausible: mega-events location decisions are complex ongoing processes that involve several rounds of negotiation and/or voting, and require active bidding and intense business plans preparation from the countries or cities that take part in the contest. Moreover in a few cases there is only one candidacy and thus the announcement conveys no news.

Stock market impact is not the same thing as overall economic impact and we do not intend to capture or test here the economy-wide benefits attributable to such events. Regardless of a positive or negative overall economic impact, individual stocks (and industry indices) may register positive abnormal returns. The same goes for the effects observed in aggregate market indices: even if investors are rational, an event yielding negative economy-wide effects does not have necessarily to have a similar correspondence in the stock market. Aggregate market returns are value-weighted averages of its individual constituent stocks' returns and, while the event may be damaging for economic growth, listed firms (and industries), that potentially extract 
direct benefits from the organization of the event such as tourism and infrastructurerelated industries, may observe positive market returns; if they represent an important share of the stock market, significant positive market returns for the aggregate index may occur. Alternatively, the event may be perceived as economically neutral for listed firms, and yet the market register positive or negative valuations due merely to market sentiment or investor myopia. It is difficult to predict a priori the sign and magnitude of market returns and relate them directly to the overall economic impact of the event. Yet one can outline hypotheses motivated by the competing theoretical arguments, and test them upon the observed zero/non-zero, positive/negative abnormal returns, symmetrical/asymmetrical effects for winning and losing countries and the crosssectional variation of returns across events.

In any case, an important question is whether investors evaluate these megaevents announcements as positive news to the companies more directly involved, and in general, to the economy of the host country. Countries and cities strongly compete to host international sporting and cultural events, and provide public funding, on the basis of the positive effects on the country's economy brought about by these events. Organizers claim that there are not only immediate increases in spending (direct and induced) but also further future economic benefits related with the infrastructure investments and international exposure. There is a lot of controversy about the true economic success of these events and about what they stand for. Several authors suggest that the true impact may be substantially lower than the one estimated in ex ante models. In fact, ex-post studies highlight that not only are the direct benefits lower (because of improper measurement of benefits and costs), but also that there is lack of empirical evidence demonstrating that the international exposure and the publicity associated with the event have any impact in improving the country or region for tourism or business. As for the companies more directly involved, previous literature suggests that stock prices tend to respond favorably to announcements of major capital investments.

We study stock market reaction to the announcement of the selected country hosting the Summer and Winter Olympic Games, the World Football Cup, the 
European Football Cup and World and Specialized Exhibitions. We also measure the market effects of the announcement of the nomination of the European Cultural City.

First, we evaluate the abnormal returns of winning bidders on (and around) the announcement date using an event study methodology. We study the impact at market and industry-levels. Second, we analyze the determinants of the variation in abnormal returns across events and industries on the basis of a set of variables found important by previous studies and control for the prior probability of observing the event. Third, on the basis of a simple model of partial anticipation, we reexamine the abnormal returns observed for winning and losing countries and perform a series of tests to disentangle the different theoretical arguments that could account for the observed stock market behavior.

Using a cross-section of 81 winning countries, we find that the abnormal returns measured at the announcement date are not consistently different from zero. We also document stock market reaction over several other event-windows and again results are inconclusive. Further, the CARs for losers are not statistically significant. When we look at particular industries, we find no evidence supporting that industries, that a priori were more likely to extract direct benefits from the event, observe stronger effects. Overall, non parametric tests seem to be more powerful but results are mixed. The results of the cross-sectional analysis confirm some of relations we predict. In particular, we document that abnormal returns are lower (in absolute terms) for winners and losers when the outcome is predictable. Overall we interpret our findings as supportive of rational asset pricing and partial anticipation. The results suggest further that non-trivial benefits exist but these are specific to particular events and countries. Thus, no general statement can be made regarding the economic merit of hosting mega-events.

This study is related with several strands of the finance and economic literature. We focus on the literature of information and market efficiency. Another strand of literature directly related to this paper is the impact of sentiment on asset prices that we indirectly address. Our results are also of interest to other empirical economic research 
areas such as economic impact studies of large capital investments and public investment in infrastructures, and sports, recreation and tourism studies.

The main contribution of our paper is to perform rigorous study of market reaction to the announcement of mega-events. Previous studies focus on one particular event and consequently do not have the opportunity to explore the cross-sectional variation in abnormal returns. Because we analyze a large number of events, we improve statistical significance and are able to explore the determinants of cross-sectional variation across events. In addition we study different types of events that can be grouped in two major classes, sporting and cultural events. On top of that, unlike most of the previous studies, we control for partial anticipation and evaluate the effects for winning and loosing countries. Our study generalizes previous results, investigates the determinants of the observed market impact and controls for the ex-ante probability of a country being a successful bidder.

While we do not address directly the overall economic benefits of these events, it is possible to draw some policy implications regarding the merit of (funding) these events. Given the limitations of traditional economic impact ex ante studies (and because the implementation of more comprehensive and rigorous techniques may be, in most cases, impracticable), event-studies looking at the market reaction to nominations may be a useful tool to indirectly assess the benefits of the organization of these events. Yet, the results of the event-study analysis have be read very carefully given that the observed abnormal returns may be contaminated by investor sentiment.

The remainder of paper is organized as follows. Section 2 reviews the relevant related literature. Section 3 presents the testable hypotheses. Section 4 presents the data and methodology. In Section 5 we present and discuss our main findings. Section 6 concludes. 


\section{Background and Previous Findings}

\subsection{Overall economic impact of mega-events}

Dwyer, Forsyth and Spurr (2005) refer mega-events as one-time or recurring events of limited duration. Mega-event projects entail large construction projects (infrastructural, productive or not) and operational costs. ${ }^{1}{ }^{2}$ Economic impact studies (or economic impact assessments), most of the times sponsored by promoters, claim these mega projects are very positive NPV projects and there seems to be a lot of interest in hosting these events. ${ }^{3}$ Yet several studies suggest that not only are the input estimates optimistic but the typical methodology to assess ex-ante event-related economic returns, inputoutput models, fail to correctly account for the revenues that are attributable to the event. ${ }^{4,5}$ To properly assess how much growth is attributable to the event, one has to a)

\footnotetext{
${ }^{1}$ For example, Germany spent over 1,4 billion euros building or rehabilitating 12 stadiums for the 2006 Soccer World Cup of which 35\% were funded by taxes (cited by Matheson, 2006). For the Beijing 2008 Summer Olympic Games, "due for completion are: a dozen Olympic sports centres; a new cross-city underground railway; a host of office towers; a massive airport terminal; and, after some delay and much criticism, a colossal French-designed egg-shaped theatre in the city centre", The Economist, March 1, 2007.

2 For example, Greece spent over 1 billion euros in the 2004 Olympic Summer Games on security (cited by Matheson, 2006).

${ }^{3}$ Matheson (2006) refers that a typical impact study usually involves estimates of the direct and induced impact: "the number of visitors an event is expected to draw, the number of days each spectator is expected to stay, and the amount each visitor will spend each day (...) subjected to a multiplier, usually around two (...). The total impact is double the size of the initial spending".

${ }^{4}$ Dwyer, Forsyth and Spurr (2005) propose a more comprehensive computable generating equilibrium model (CGE) to assess the economic impact of such events.

5 "Officials estimate that the Olympics have been contributing more than two percentage points to Beijing's annual growth since 2003. After the games, they insist, the city's new infrastructure and additional glamour (including the egg-shaped theatre, which hopes to attract international stars) will help keep the economy rolling. The flow of investment will be sustained, they say, by further infrastructure development, and by the pent-up demand for property, which will be supported by a continuing large influx of migrants from the countryside.", The Economist, March 1, 2007.
} 
control for "substitution" and "crowding-out" effects ${ }^{6}$ - even when demand is mostly non-resident or even foreign -; b) incorporate multipliers that reflect eventual "leakages to other countries"; 7 and c) account for the impact in taxation or government borrowing. ${ }^{8}$ More refined models propose using a series of relevant variables, proxy factors for local growth determinants, to project the level of economic activity in the absence of the event. Comparing this estimate with the actual level of activity will tell us expost what the effective contribution of the event was. In other words, deviations from average national (or local) growth or historical growth, that are not explained by deviations in costs of production or demand side variables, should be attributed to the event.

There is some controversy regarding the economy-wide impact of mega-events in the host countries. The impact is measured frequently by changes in personal income, per capita personal income, employment and taxable sales or sale taxes collections. Academic studies that analyze the ex post effects of these mega-events confirm that ex ante estimates are overly optimistic. For example, Baade and Matheson (2004) present an expost analysis of the 1994 World Cup in the U.S. and find that several cities did in fact

\footnotetext{
${ }^{6}$ Ex-ante effects often ignore "substitution" and "crowding-out" effects. For example, local residents that are willing to join the event activities may not spend as much in other leisure activities and/or cut leisure travel to other cities in the country. On the other hand, due to the fixed number of hotel rooms and high prices or simply to avoid the event crowd, regular tourists and business travelers may prefer to go elsewhere and these lost visitors may have more attractive spending patterns.

7 To estimate the output and jobs generated by the additional demand brought about by the event it is necessary to take in consideration whether inputs are variable or fixed. There could be capacity constraints in factors such as labor. For example, in many of these events, infrastructure building requires using resources that were required by other activities or hiring foreign workers whose subsequent spending patterns may be atypical. The benefits may not go all to the host country but to foreign neighbor countries or multinationals and there could be damages to other productive sectors in the economy. For example, all the 16 the official partners for the 2006 FIFA World Cup in Germany were multinationals and only two were German. Yet all the official suppliers were German companies.

8 Public funding is often required for the event infrastructures. This could imply that other potential more productive investments are not funded (or postponed) or taxes have to rise (Siegfried and Zimbalist, 2000). Those public expenditures may or not have positive impact on the economy. Sporting events specialized infrastructures such as stadiums or swimming pools have a limited use and potentially benefit only a small part of the tax payers that paid for it. More general construction projects, for example, related with the World Expositions, such as cities core redevelopment and infrastructure building may benefit more directly the country or local community. Similarly, the benefits from investing in cultural or lifestyle amenities such as theatres and first-rate architecture museums, or urban parks, biking and foot trails, can attract highly educated and creative young people that are essential to economic growth.
} 
experience significant losses in contrast with the gains estimated by the tournament promoters. ' The most recent and sophisticated ex post studies, seem to suggest no consistent positive statistically significant net economic benefits (Matheson, 2006). ${ }^{10}$ In any case, several authors notice that it is difficult to isolate the impact of the event and given that it is likely to be small relative to the overall economy, one may not be able reject the null of no economic benefits even if true benefits occur.

\subsection{Market impact of investment decisions}

The extensive event study literature focusing on announcement effects provides evidence that, on average, stock price reaction is consistent with market efficiency: prices rapidly and fully adjust to the release of new corporate information. ${ }^{11}$

\subsubsection{Market reaction to major capital investments}

Capital expenditures decisions are the key financial decisions in terms of contribution to firm-value (Miller and Modigliani, 1958).

Under the null hypothesis of efficient markets, the announcement effects on market prices should reflect the significance of any unexpected news that influence cash flows or discount rates (McQueen and Roley, 1993). Stock prices at time $t$ are given by:

$$
P_{t}=E\left[\sum_{\tau=1}^{\infty} \frac{D_{t+\tau}}{1+{ }_{t} R_{t+\tau}} / \Omega_{t}\right]
$$

\footnotetext{
${ }^{9}$ The authors suggest that host cities accumulated losses of US $\$ 5,5$ to US $\$ 9,3$ billions as opposed to the US $\$ 4$ billion gain estimated by the organizers.

10 Please refer to Matheson (2006) for an extensive survey of ex ante and expost economic impact studies (tables 1 and 2).

${ }^{11}$ For throughout reviews, see, for example, Fama (1991) and Dimson and Mussavian (1998). Several recent studies present evidence contrary to market efficiency suggesting either overshooting in prices or gradual information dissemination. In recent years several behavioral finance models have been proposed to account for overreaction and underreaction but no single model has been able to fully explain and integrate these anomalies (Fama and French, 1998).
} 
where

$D_{t+\tau}$ are the expected dividends at time $t+\tau$;

${ }_{t} R_{t+\tau}$ is the expected discount rate at time $t+\tau$; and

$E\left[. / \Omega_{t}\right]$ are the conditional expectations upon the available information set $\Omega$ at time $t$.

Theoretically there are three alternative stock market reactions to announcements of capital expenditures plans (Woolridge and Snow (1990 and Burton, Lonie and Power (1999)):

- the first hypothesis predicts a positive market reaction on the assumption that managers maximize shareholder wealth and undertake positive-NPV projects; hence the larger the economic valued added by these projects, the larger the positive impact. A zero or negative effect requires that these announcements are not fully anticipated and managers only engage in positive NPV projects.

- the second hypothesis predicts that the impact of the announcements is null because investors have perfect foresight and fully anticipate future positive NPV projects; therefore prices incorporate its net benefits even before new capital expenditures are announced. The market value of a company would already reflect the impact of these or other investments that the firm would have to pursue to maintain its (anticipated) competitive advantages. Under this hypothesis, the fact that the market does not react to the announcements is not informative about the economic merit of these mega-events;

- finally the third hypothesis predicts that the impact of the announcements of capital investments is negative based on the assumption that investors are myopic. As such, they pay too much attention to short-term earnings and penalize long-term capital investments.

Previous empirical literature finds support to the first hypothesis: on average, stock prices seem to respond favorably to announcements of individual firms major 
capital investments. ${ }^{12}$ Further, the stock market reaction is greater, the level of new investments announced. McConnell and Muscarella (1985) show that firms' stock market responses to capital expenditures announcements reflect their investment opportunities. Similarly, Bloose and Shieh (1997) show the market response is larger to announcements of firms with good investment opportunities. Yet Titman et al. (2004) show that increased investment expenditures may be associated with negative stock returns reflecting that investors underreact in fear of "empire building" decisions. ${ }^{13}$

\subsubsection{Mega-events}

Mega-events announcements may produce a short-term impact on the stock prices of the listed companies that may benefit directly from the event such as construction and building materials, tourism-related, communications and media companies. ${ }^{14}$ More long-term effects could also arise due to general multiplier effects and, even more important, as a result of country projection. Merton (1987) refers to changes in investor recognition as a source of value. Investors only invest in the assets they are aware and require higher returns to compensate for the shadow cost of incomplete information. Organizing a large event such as the Olympic games, can overrun that cost and, through an expansion of shareholders' base, lead to a decrease in required returns translating into higher stock market valuations. The increased exposure to international media may also produce long term benefits through increased tourism receipts in the years after the event.

\footnotetext{
12 See, for example, Woolridge and Snow (1990), Jones, Danboldt and Hirst (2000) and Titman, Wei and Xie (2004) and references therein.

${ }^{13}$ Related with this is what is sometimes designated by Capital Myopia that refers to excessive investments pursued by companies that erroneously believe that there is scope for further profitable capital investments ignoring that competition will drive away economic rents. If investors anticipate that, a negative market reaction may be observed.

14 Preto (2004) analyses the impact of the 2004 UEFA European Football Championship on listed Portuguese companies. The author identifies six companies that could benefit directly from the event. These are Portugal Telecom (telecommunications), Brisa (motorways), Impresa (media), Sonaecom (mobile operator), Ibersol (fast-food restaurant chain) and BPI (banks, official event sponsor).
} 
Veraros, Kasimati and Dawson (2004) examine the effect of the announcement of the hosting city for the 2004 Olympic games on the stock exchange of Greece and Italy and finds a significant positive effect on the Athens Stock Exchange as well as on the stock prices of infrastructure-related companies. ${ }^{15}$ Yet no (negative) effect is observed for the losing country stock market (Milan Stock Exchange).

\subsubsection{Partially-anticipated events}

Stock price changes on the announcement date may only reflect a part of the overall effect of an event if investors partially anticipate the event. Market reaction to announcements depends on investors' perception of the likelihood of the event. Variation in market reaction to the announcement of a particular event may merely reflect the degree of anticipation. The announcement effect is most of the times smaller than the economic impact of the event and failure to document significant announcement returns may be explained by partial anticipation. Stock prices may as well reflect investor disappointment if investors had prior expectations on the occurrence of events with positive value than do not materialize (Malatesta and Thomson, 1985). Several studies have estimated the likelihood of observing an event based upon firms characteristics and found that the extent of market reaction is affected by investors' prior expectations. ${ }^{16}$

\subsubsection{Investor sentiment}

Several authors document that changes in investor mood are associated with changes in market prices. Thus, prices could move regardless of the true economic impact of these events or the degree of anticipation associated. Recent literature shows that events that have a general impact on investor sentiment, such as national team soccer results,

15 A similar study conducted by G. Berman, R. Brooks and S. Davidson ("The Sydney Olympic Games announcement and the Australian Stock market react", Applied Economic Letters, 2000, Vol. 7, pp. 781-84), cited by Veraros et al. (2004) found no significance effect on the overall market, and only limited effects on stock prices of infrastructure development companies based in New South Wales where the Olympic Games were hosted.

16 See, for example, Acharya (1993) or Akhigbe, Madura and Whyte (2004) and references therein. 
produce statistically and economically significant returns. For example, Edmans, Garcia and Norli (2007) find that a loss in World Cup leads to a next-day abnormal return of 38 basis points, and claim that this loss effect is driven by investor sentiment.

\section{Development of hypotheses}

We evaluate the following hypotheses:

(i) The announcement of a mega event such as the Olympics, the World Football Cup, the European Football Cup or the World Exposition is associated with a positive market reaction on the nominated country stock exchange. ${ }^{17}$

A significant positive average market reaction for the winning country is consistent with shareholder value maximization but could also reflect investors' sentiment. A negative market reaction for the winning country may reflect either that investors are myopic, or that managers invest in negative NPV projects for their own benefits. A null impact may reflect that investors have fully anticipated the effects of the event. $^{18}$

(ii) The announcement of a mega event such as the Olympics, the World Soccer Cup, the European Soccer Cup or the World Exposition is associated with a negative market reaction on the losing country stock exchange.

A significant negative market reaction for the losing country is consistent with either shareholder value maximization when there is partial anticipation, or reflect investors' sentiment. The positive/negative effects can be asymmetric reflecting that there are differential net potential benefits for the economies of the winning/losing countries. A stronger (negative) effect for losing countries is consistent with behavioral arguments.

17 The statistical null hypothesis tested in Section 5 is that the impact of the announcement of the event is null and so forth for the other hypotheses.

18 A null impact may also reflect that the effects are trivial. 
(iii) Individual industries that potentially benefit more from the event exhibit higher market reaction.

A similar price impact across industries, regardless of the potential economic benefits they can extract from the event, is consistent with investor sentiment arguments.

(iv) Abnormal returns (for the winning countries) vary across events and industries and are driven by the relative importance of the event (relative to the underlying economy), the time-span between the announcement and the realization of the event, and the degree of partial anticipation.

Significant differences in the cross-section of abnormal returns are evidence against behavioral arguments that predict that the observed effects derive simply from investor sentiment.

The predictions of the different theoretical arguments are as follows:

\begin{tabular}{|c|c|c|c|c|}
\hline \multirow[b]{2}{*}{ Observed Effects } & \multicolumn{4}{|c|}{ Theoretical Arguments } \\
\hline & $\begin{array}{c}\text { Shareholder } \\
\text { Maximization Hypothesis }\end{array}$ & $\begin{array}{c}\text { Rational } \\
\text { Expectations }\end{array}$ & $\begin{array}{l}\text { Myopic } \\
\text { Investors }\end{array}$ & Sentiment \\
\hline \multicolumn{5}{|l|}{ Winning country } \\
\hline$>$ aggregate stock market impact & $\begin{array}{l}\text { +ve } \\
\text { it could -ve reflecting } \\
\text { agency conflicts }\end{array}$ & null & -ve & $+\mathrm{ve}$ \\
\hline \multicolumn{5}{|l|}{$>$ more positive impact for selected } \\
\hline industries & $\checkmark$ & $x$ & $x$ & $x$ \\
\hline \multicolumn{5}{|l|}{ Losing country } \\
\hline$>$ aggregate stock market impact & $\begin{array}{c}\text {-ve } \\
\text { if anticipation }\end{array}$ & null & null & -ve \\
\hline \multicolumn{5}{|l|}{$\underline{\text { Winning and Losing countries }}$} \\
\hline$>$ variation across markets/events & $\checkmark$ & $x$ & $\checkmark$ & $x$ \\
\hline \multicolumn{5}{|l|}{ related to } \\
\hline - SIZE & $\checkmark$ & & $x$ & \\
\hline 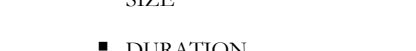 & $x$ & & $\checkmark$ & \\
\hline - ANTICIPATION & $\checkmark$ & & $x$ & \\
\hline$>$ asymmetry & $\begin{array}{c}\checkmark \\
\text { differential economic } \\
\text { benefits }\end{array}$ & $x$ & $x$ & $\checkmark$ \\
\hline
\end{tabular}




\section{Data and Empirical tests}

In this section we describe the tests we propose to evaluate these hypotheses and to disentangle the competing theoretical arguments.

\subsection{Data}

Announcement dates were gathered from several sources (through mail contact or websites): IOC (International Olympic Committee) for the Summer and Winter Olympic Games; FIFA (Fedération Internationale de Football Association) for the World Football Cups; UEFA (Union des Associations Européennes de Football) for the European Football Cups; Bureau International des Expositions for the World and Specialized Exhibitions; and the EC (European Commission) for the European Capitals of Culture. Please refer to appendix A for details.

The sampling criterion was availability of daily of country and industry indices returns with at least half a year before the event. The final sample consists of 81 announcements. ${ }^{19}$ Table A.1. in appendix lists the announcement dates. The first announcement date is May 16, 1955 and refers to the 1960 Summer Olympic Games hosted by Italy. The last announcement date in our sample is July 2, 2003 and refers to the 2010 Winter Olympic Games that will be hosted by Canada. The average lag between the announcement and the realization of the mega.events for the 81 events is 57.5 months.

${ }^{19}$ Some events are co-organized by two or more countries. For example Belgium and Netherlands organized the 2000 European Football Cup together. In that case we consider them as separate observations. 
[TABLE 1 HERE]

Table 1 shows the breakdown of the events analyzed by type of event and by organizing country. ${ }^{20}$ Our sample includes 6 Summer Olympic Games (1984 onwards), 8 Winter Olympic Games (1988 onwards), 6 World Football Cups (1990 onwards), 10 European Football Cups (1984 onwards), 11 World Exhibitions (1982 onwards), 10 Specialized World Exhibitions (1980 onwards) and 30 European Capitals of Culture (1986 onwards). Even after excluding the European Capitals of Culture, Europe has been the most successful venue attracting these events. Worldwide, by country, the US is the top organizer followed by Japan, Canada, Germany and Italy.

We also gathered information for the losing candidacies when available. This information, shown in table 2, was only available for a subset of events and dates. ${ }^{21}$ The most active (not successful) bidder is Canada followed by Sweden.

\section{[TABLE 2 HERE]}

Returns for the winning and losing countries were obtained from Datastream and computed using a total return index measured in US dollars. ${ }^{22}$

For the multivariate analysis we use GDP and industrial production index data from IMF. Market capitalization data was obtained from Datastream. The Olympic Games voting results for the several rounds were obtained from Lyberg, Wolf "Fabulous 100 years of the IOC; facts, figures and much, much more", Lausanne, 1996,

\footnotetext{
${ }^{20}$ There are a few cases for which there is no market information for the winning country when the nomination was announced. For example, this is true for the 1988 Summer Olympic Games in the former Soviet-Union or the 1988 Winter Olympic Games in Korea.

21 Stock market information was not available for several losing countries by the time of the nomination announcement (for example, China, in respect to the 2000 Summer Olympic Games or Morocco, in respect to the 1998 and 2002 World Football Cups).

${ }^{22}$ Datastream indices were preferred over other domestic market and industry indices when available because they are constructed on a uniform basis across markets and are not backfilled with firms added or deleted from the index. The exception was the total return series for Spain general index (IBEX) obtained directly from Bolsa de Madrid.
} 
pp. 308-313 and from the IOC website. The World Football Cup voting results were provided by FIFA. Appendix A describes the voting procedures. Table 3 summarizes the voting results for the winning and the losing second more voted countries over the several rounds.

[TABLE 3 HERE]

\subsection{Empirical framework}

First we use a traditional event study approach to evaluate hypotheses (i), (ii), and (iii). For each market (or industry within a market) we estimate expected returns on the basis of a selected return generating process; then, we compute abnormal returns at and around the announcement date (and obtain variance/covariance information); we aggregate abnormal returns across markets and infer about the average effect. ${ }^{23}$

Second, we run cross-sectional regressions of the abnormal returns on the variables potentially influencing the magnitude of the market reaction to the mega-event announcements (and evaluate hypothesis $i v$ ).

Third, we run further tests to analyze the role of partial anticipation and disentangle rational and behavioral arguments.

\subsubsection{Abnormal returns}

The methodology employed to measure the magnitude of stock price reactions to announcements is the standard abnormal returns technique based upon the several benchmarks described below.

\footnotetext{
${ }^{23}$ To estimate and infer about the average impact of the event several other frameworks could be used. For example, one could jointly estimate, for each market, the return generating process parameters using time-series and the event impact by including a dummy that would be equal to 1 at the time of the announcement and 0 otherwise. The third step then would be similar: compute the cross-sectional average economic impact of the event by aggregating the individual firm parameters and infer. Most of the studies that analyzed mega-events perform only the first two steps, i.e., they only evaluate the significance of the effects for a single market.
} 
We examine the impact of the nomination on returns as of the announcement date. We analyze several other windows to account for partial anticipation and leakages in information or delayed effects due to thin trading.

Daily abnormal returns were calculated using constant-mean, market-adjusted and risk-adjusted methods described in Brown and Warner (1985). ${ }^{24}$ The date of the announcement is designated as day $t=0$. Daily returns are collected for the period ( $t=$ 140 to 20$)$. The estimation and event periods were defined respectively as [-140, -21] and $[-20,20]$.

Abnormal returns, $\mathrm{AR}_{i p}$ are obtained as the difference between observed (log) returns of the country $i$ at event day $t, R_{i t}$, and the expected return generated by a chosen benchmark $\mathrm{E}\left(\mathrm{R}_{i t}\right) . \mathrm{E}\left(\mathrm{R}_{i t}\right)$ is defined as follows, respectively for the constant-mean return, the market-adjusted and the risk-adjusted methods:

$$
\begin{aligned}
& E\left(R_{i t}\right)=1 / 120 \sum_{t=-140}^{-21} R_{i t} \\
& E\left(R_{i t}\right)=R m_{t} \\
& E\left(R_{i t}\right)=\hat{a}+\hat{b} R m_{t}
\end{aligned}
$$

The presence of unequal integration of the countries analyzed makes it difficult to find a good model to the pricing of these securities. We assume that the degree of segmentation is fixed through the period of estimation of risk exposures and that markets are fully integrated with the world market. We thus use an unconditional world market model. Parameters $a$ and $b$ were estimated regressing market index returns on the world market index over the estimation period.

\footnotetext{
${ }^{24}$ Kothari and Warner (2006) show that the tests are not highly sensitive to the benchmark model of abnormal returns. Market-adjusted returns are not included here for all tests. Results are available upon request.
} 
Averaging abnormal returns across markets in common event time, we obtain the average cross-sectional abnormal return given by:

$$
A R=1 / N \sum_{t=1}^{N} A R_{i t}
$$

where $N$ is the number of countries in the sample.

By cumulating the average residuals over a particular time interval $\left(-20<t_{1}<=0\right.$; $0=<t_{2}<20$ ), we obtain the cumulative average abnormal returns $(C A R)$ as follows: ${ }^{25}$

$$
C A R\left[t_{1}, t_{2}\right]=\sum_{t=t_{1}}^{t_{2}} A R_{t}
$$

The procedure is similar when we analyze the effects for a particular industry. $C A R$ are computed by first averaging daily abnormal industry returns across markets and then cumulating industry average abnormal returns over the days that comprise the event window under scrutiny. ${ }^{26}$ To compute industry returns we use the 32 Datastream industry-level 4 index series.

We use both parametric and non-parametric tests to assess the statistical significance of average abnormal returns. The use of several tests aims at ensuring the robustness of results when the usual assumptions of independence in the cross-section, constant variance or normality of returns are incorrect. ${ }^{27}$ The parametric test statistics

\footnotetext{
${ }^{25}$ Because we use continuously compounded returns, buy and hold returns for a specific time-span are achieved by simply summing the log returns. If we assume that discrete returns are distributed as iid log normal variables, cumulative log returns are normal distributed.

26 The benchmarks to compute industry market- and risk-adjusted abnormal returns was the country's total return market index.

27 Kothari and Warner (2006) show that with short horizons, the usual test statistic is not highly sensitive to assumptions about the cross-sectional or times-series dependence or normality of returns. Further, they show that short horizon event study tests are generally well-specified but the power of the tests is sensitive to sample size and firm characteristics (such as volatility). For firms with low volatility, sample size of 20 is enough attain full power for a $1 \%$ abnormal return.
} 
examined are Brown and Warner $(1980,1985)$ with and without crude dependence adjustment, the standardized residual test and Boehmer, Musumeci and Poulsen (1991) standardized cross-sectional test. The non-parametric statistics are the sign test, Corrado (1989)'s rank test and Wilcoxon-signed rank test. ${ }^{28}$ Please refer to Serra (2004) for details.

\subsubsection{Cross-sectional analysis}

To estimate the impact of the determinants on the cross-sectional variation of abnormal returns (and test hypothesis $(i v)$ ), we estimate the following equation using fixed effects for industries: $:^{29}$

$$
\begin{aligned}
& \operatorname{CAR}_{j \mathrm{~s}}=\beta_{0}+\beta_{1} \mathrm{SIZE}_{j}+\beta_{2} L A G_{j}+\beta_{3} L I Q_{j}+\beta_{4} R E C_{j}+\beta_{5} E X P_{j}+ \\
& +\beta_{6} R E P_{j s}+\beta_{7} V O T_{j}+\sum_{k} \gamma_{k} D_{k}+\eta_{j s}
\end{aligned}
$$

where

$C A R_{j s}$ are the cumulative abnormal returns for industry $s$ (in host country $j$ );

$S I Z E_{j}$ is the ratio between the event capital expenditure and the host country $j$ GDP;

$L A G_{j}$ is the time lag between the announcement and the moment of the event hosted by country $j$;

$L I Q_{j}$ is the ratio between country $j$ market capitalization and its GDP;

$R E C_{j}$ is a dummy that equals 1 if the economy is in recession at the time of the event hosted by country $j$ and 0 otherwise;

$E P_{j}$ is a dummy that equals 1 if the economy is in expansion at the time of the event hosted by country $j$ and 0 otherwise;

\footnotetext{
${ }^{28}$ The tables below report the statistics for the usual Brown and Warner $(1989,1985)$ parametric tests and for the sign test. Other results are available upon request.

${ }^{29}$ We run the same regression for market CARs (instead of industry CARs) using OLS (instead of fixed effects) without the industry-specific variable REP.
} 
$R E P_{j s}$ is the ratio of industry $s$ market capitalization and the overall capitalization of country $j$ stock market;

$V O T_{j}$ is the difference in the percentage of votes between winning country $j$ and the losing country with the largest number of votes in the last round;

$D_{k}$ are dummies for each type of event (Olympic Games, etc.); and $\eta_{j s}$ is an i.i.d. error term.

The variable SIZE is motivated by Burton et al. (1999) that report that the market impact of capital expenditures announcements is stronger for larger projects. Yet, the findings of Woolridge and Snow (1990) do not confirm this relation. Given that we are comparing countries with very different economy sizes we use relative instead of absolute size. ${ }^{30}$

The variable $L A G$ proxies investors' myopia. Burton et al. (1999) and Woolridge and Snow (1990) fail to find any significant different effect in market reaction between long-term and short-term project announcements.

Our main variable of interest is VOT. We expect that the smaller the difference in the percentage of votes between the two candidates in the last round, the larger the surprise in the announcement news and therefore the larger the impact on prices.

We also control for a set of variables found important by previous studies. LIQ tries to capture how well the economic output of a particular country is mirrored in its stock market. REP is an industry-specific variable to control for the importance of a particular industry in the stock market. To accommodate the findings of McQueen and Roley (1993) that report a negative relation between market impact and economic activity, we also include the variables REC and EXP. These variables proxy economywide activity. We follow McQueen and Roley (1993) methodology to define economic

\footnotetext{
30 Veraros et al. (2004) argue that the difference in the reaction of Athens and Milan stock exchanges could result from economy size differences (Greece and Italy) and the importance of the two cities potentially hosting the event (Athens and Rome) and, as such, a much stronger effect on the national economy of Greece.
} 
states. ${ }^{31}$ Finally, we include dummies for the type of event and allow for industry fixed effects to account for differential benefits across industries.

\subsubsection{Partially Anticipated Effects}

We analyze two specifications to evaluate the role of partial anticipation.

\section{Partial Anticipation I}

On the basis of the model derived in appendix B, we propose the following empirical testable model:

$$
C A R_{i}=\alpha+\phi p_{i}+\delta D_{i}+\mu_{i}
$$

where

$C A R_{i}$ are the cumulative abnormal returns over the event window for country $i$ aggregate market index; $(i=$ winners, losers $)$

$p_{\mathrm{i}}$ is defined as the probability of country $i$ hosting the event;

$D_{\mathrm{i}}$ is a dummy variable that equals 1 if the country $i$ is nominated and 0 otherwise; and

$\mu_{i}$ is a i.i.d. error term.

To estimate $\alpha, \phi$ and $\delta$ we pool the cumulative abnormal returns of the winning and losing countries across events.

If the country is chosen to host (or not host) the event, expected abnormal returns are given by, respectively:

\footnotetext{
${ }^{31}$ McQueen e Roley (1993): "We use the seasonally adjusted monthly industrial production index, to define economic states. First, we estimate a trend in log of industrial production by regressing the actual log of industrial production on a constant and a time trend. Then we add and subtract a constant from the trend, creating the upper and lower bounds ... so that the log of industrial production is above the upper bound, denoted as "high" economic activity, 25 percent of the time. The log of industrial production is below the lower bound, indicating "low" economic activity, about 25 percent of the time as well. "Medium" economic activity is represented by the remaining observations between the bounds."
} 
$E\left(C A R_{j}\right)=\overbrace{\hat{\alpha}+\hat{\phi} p_{j}+\hat{\delta}}^{\text {Unanticipated effect for Winner }}$

$E\left(C A R_{l}\right)=\overbrace{\hat{\alpha}+\hat{\phi} p_{l}}^{\text {Unanticipated effect for Loser }}$

Given the expressions $(A-4)$ and $(A-5)$ in appendix

$\phi=-\frac{N P V_{l}}{V_{l-1}\left(1+E\left(R_{l}\right)\right)}$

$\delta=\frac{\left(1-p_{j}\right) N P V_{j}}{V_{j-1}\left(1+E\left(R_{j}\right)\right)}-\phi p_{j}$

$=\frac{\overbrace{\left(1-p_{j}\right) N P V_{j}}^{\text {Unanticipated effect }}}{V_{j-1}\left(1+E\left(R_{j}\right)\right)}+\frac{N P V_{l}}{V_{l-1}\left(1+E\left(R_{l}\right)\right)} p_{j}$

where $\mathrm{V}_{j-1}$ and $\mathrm{V}_{l-1}$ denote, respectively, the winning country $j$ and the losing country $l$ market valuation just before the event is announced; $N P V_{j}$ and $N P V_{l}$ stand for the economic impact of the event for each country.

Rational arguments yield the following predictions:

- $\alpha=0, \phi<0, \delta>0$

Assuming that the effects observed reflect solely the economic impact of the event (i.e., $\alpha=0), \delta$ and $\phi$ will capture all the relevant effects. $\phi$ reflects that stock prices 
will adjust downwards for the losing country in the unanticipated effect (that the country would lose). $\phi p_{j}+\delta$ reflects the upwards adjustment in stock prices for the winning country in the unanticipated effect (that the country would win). If the economic impact of the event was similar for the two countries (in percentage of its actual market capitalization), $\delta$ would capture the total economic impact of the project. Ceteris paribus, the greater the impact of the project (NPV), the larger the magnitude of the parameters, $\delta$ and $\phi$. When the event is not anticipated at all, $\delta$ captures the full economic impact for the winning country $\left(E\left(C A R_{j}\right)=\delta\right.$ and $\left.E\left(C A R_{j}\right)=0\right)$.

If stock prices are influenced by sentiment, the above parameters must be reinterpreted. Given that the parameter $\delta$ could now reflect the effect of positive sentiment, and assuming that in that setting parameter $\phi$ could be disregarded $(\phi=0$, prices would be affected by investor sentiment, regardless of the objective probability of observing the event), $\alpha$ would capture the negative sentiment in prices. Further, if sentiment effects are more pronounced when the country looses, then $|\alpha|>|\delta|$.

The testable predictions for the behavioral arguments are the following.

- $\delta>0$ and $\alpha<0$ (positive sentiment for winners and negative sentiment for losers);

- $|\alpha|>|\delta|$ (asymmetric sentiment effects);

Notice that if the $\alpha$ estimate is negative and significantly different from zero, one can disentangle rational and behavioral arguments.

\section{Partial Anticipation II}

To account for market expectations in (8), we use the percentage of votes received by the country in the last round. This may be considered an objective prior probability assuming rational expectations. Yet, the selection process is highly competitive and, in the successive rounds of voting, the ranking is often reversed, and front runners are many times overtaken by other candidates. One could argue that 
initial and intermediate rankings also influence investors' expectations. To account for that, we tested the following alternative specification:

$$
C A R_{i}=\varphi_{0}+\varphi_{1} P S_{i}+\varphi_{2} T S_{i}+\lambda_{0} D_{i}+\lambda_{1} D_{i} P S_{i}+\lambda_{2} D_{i} T S_{i}+\omega_{i}
$$

where

$C A R_{i}$ and $D_{\mathrm{i}}$ are defined as in (8); ( $i=$ winners, losers)

$P S_{i}$ is a dummy variable that equals 1 when the announcement news are a partial surprise and 0 otherwise;

$T S_{i}$ is a dummy variable that equals 1 when the announcement news are an almost total surprise and 0 otherwise; and

$\omega_{i}$ is an i.i.d. error term.

The specification (13) accommodates the fact that investors form their expectations on the basis of all rounds of voting. Further we also take into account the country bidding record. The motivation for including this piece of information is grounded on the idea that the selection outcome is influenced by the lobbying power of the candidacies (Veraros, et al. (2004)): if the country did bid for hosting the last event and lost, investors may perceive that the lobbying power is limited and anticipate that, once again the candidacy will not succeed.

We classify the announcement news as total surprises, out of line to market expectations, when:

- for the winning country, the country did not consistently lead the ranking in the previous voting rounds, and had bid for hosting the previous event;

- for the losing country, the country lead the ranking in some of the previous voting rounds, and had not bid for hosting the previous event.

Announcement news are classified as partial surprises when:

- for the winning country, the country consistently lead the ranking in all the previous voting rounds, and had bid for hosting the previous event; or the country did 
not lead the ranking in all previous voting rounds but had not bid for hosting the previous event.

- for the losing country, the country never lead the ranking in the successive voting rounds, but had not bid for hosting the previous event; or the country lead the ranking in only one of the previous voting rounds but had bid for hosting the previous event.

Expected abnormal returns for the winning and losing bidders for the cases of total surprise and partial surprise can be summarized as follows:

\begin{tabular}{ccc}
\hline Surprise/Country & Winning & Loosing \\
\hline No Surprise & $\varphi_{0}+\lambda_{0}$ & $\lambda_{0}$ \\
Partial Surprise & $\varphi_{0}+\varphi_{1}+\lambda_{0}+\lambda_{1}$ & $\varphi_{0}+\varphi_{1}$ \\
Total Surprise & $\varphi_{0}+\varphi_{2}+\lambda_{0}+\lambda_{1}$ & $\varphi_{0}+\varphi_{2}$ \\
\hline
\end{tabular}

Rational arguments yield the following predictions for the winning country:

$$
\begin{aligned}
& -\varphi_{0}+\lambda_{0}=0 ; \varphi_{0}+\varphi_{1}+\lambda_{0}+\lambda_{1}>0 ; \varphi_{0}+\varphi_{1}+\lambda_{0}+\lambda_{2}>0 \text {; and } \\
& \varphi_{0}+\varphi_{2}+\lambda_{0}+\lambda_{2}>\varphi_{0}+\varphi_{1}+\lambda_{0}+\lambda_{1} .
\end{aligned}
$$

As for the losing country, the predictions are:

- $\varphi_{0}=0 ; \varphi_{0}+\varphi_{1}<0 ; \varphi_{0}+\varphi_{2}<0 ;$ and $\left|\varphi_{0}+\varphi_{2}\right|>\left|\varphi_{0}+\varphi_{1}\right|$.

If there is no surprise, abnormal returns as of the announcement date should be null. The greater the surprise, the greater the positive (negative) impact of the nomination news for the winning (losing) country.

Behavioral arguments predict that:

- $\varphi_{0}+\lambda_{0}>0 ; \varphi_{0}<0$; and $-\varphi_{0}>\lambda_{0} / 2$ (asymmetrical effect).

As in (8), if prices were affected by investor sentiment, regardless of the objective probability of observing the event, the behavioral effect would be subsumed by parameters $\varphi_{0}$ and $\lambda_{0}$. 


\section{Results}

In this section we present and discuss the observed valuation effects as of the date of the announcement of the country nomination to host a mega-event, as well as the findings in terms of what factors drive the observed results. Section 5.1 discusses the magnitude and significance of the observed abnormal returns at the announcement date. Section 5.2 presents the results for the cross-sectional analysis and section 5.3. presents the estimates for the proposed model specifications of partial anticipation.

\subsection{Abnormal returns}

The average abnormal returns are shown in tables 4, 5 and 6. Table A.2 in appendix shows the abnormal results for each individual host country.

\subsubsection{Winning Countries}

Aggregate Market Reaction

\section{[TABLE 4 HERE]}

The first hypothesis that we test is whether the announcement of a mega-event is associated with a positive stock market reaction on the nominated country. Table 4 shows the abnormal returns at and around the moment the nomination information was released, for each type of event. The table shows the abnormal returns controlling for worldwide market effects that we assume to be unaffected from that particular country specific event. We present market-model and mean-adjusted CARs and significance tests for four windows of interest: $[-1,1],[0,0],[0,1]$ and $[0,5] .^{32}$

32 We looked upon other significance parametric and non parametric tests. Results are not reported here to save space. The significance of the results discussed in the paper is barely unchanged. 
We observe no significant stock market reaction at the announcement dates. This is true for all the events we analyze except for a positive reaction at the announcement of Specialized Exhibitions: the sign test shows that 8 out the 10 countries in sample showed a positive abnormal return. Overall the magnitude of the observed market reaction is economically and statistically insignificant.

The magnitude and significance of the CARs for the other windows analyzed is not significantly from zero with two exceptions: market-model CARs register a positive significant effect for the Specialized Exhibitions over the window periods $[0,1]$ and $[0,5]$; and there is a negative significant CAR [-1,1] for the European Capitals of Culture. In both cases the results are barely significant and only if we use non-parametric tests.

The evidence does not suggest a differential market reaction for sport or cultural events. The only statistically significant result we observe regards a cultural event but the relation could be spurious.

\section{Individual Markets Reaction}

As noted above, we expect that the impact varies across events and markets reflecting several factors such as the importance of the event relative to the underlying economy or the degree of partial anticipation. The results in table 4 could thus reflect that there is considerable variation across individual markets. Table A.2 in appendix shows the stock market abnormal returns for each nominated country. We concentrate here on the effects at the announcement date $[0,0]$. We observe that some markets experience positive returns while others experience negative returns but in most cases these are not statistically significant.

We observe significant positive abnormal returns for:

- Greece (+7.8\%), regarding the announcement of the nomination to host the 2004 Olympic Games; this result is consistent with Veraros et al. (2004) They 
find that upon the announcement of the nomination, there was a positive and significant effect on the Athens Stock Exchange general index; ${ }^{33}$

- Sweden (+1.5\%) regarding the 1992 European Football Cup;

- China (+1.9\%, marginally significant at 10\%) regarding the 2010 World Exhibition;

- Belgian (+0.95\%) regarding the 2000 European Capital of Culture.

As for the significant negative abnormal returns, these are:

- the US (-2.6\%) regarding the 1980 Winter Olympic Games;

- Italy (-1.7\%) regarding the 1990 World Football Cup;

- Germany (-1.1\%) regarding the 1988 European Football Cup;

- Netherlands (-1.3\%) regarding the 2000 European Football Cup;

- Spain (-1.6\%) regarding the 1992 World Exhibition;

- Sweden (-2.5\%), Germany (-2.0\%), Czech Republic (-1.4\%) respectively, regarding the European Capitals of Culture of 1998, 1999 and 2000.

These negative reactions are consistent with myopic investors that penalize longterm investments. ${ }^{34}$

Thus, regarding our first hypothesis, we cannot reject the null of no significant average aggregate market reaction to the announcements of hosting country nominations. The individual market analysis suggests that some markets react positively to the announcement of mega-events while others react negatively. Yet, overall, the effect is trivial and, on average, not significantly different from zero. The results hold across different event categories. The findings seem to be fairly robust: abnormal performance remains economically and statistically insignificant at and around the announcement date regardless of the model we use to compute abnormal returns or the chosen parametric or non parametric test we use to assess significance.

\footnotetext{
${ }^{33}$ Yet the authors document that there were no significant effects on the general index for the losing country (Italy).

34 Alternatively one could argue that the market perceives these (in most cases public) investments as economy-wide damaging projects. The reasons for pursuing these mega-projects would have to be mostly political.
} 
This non-significant average impact is consistent with rational expectations. Yet the results of the individual market analysis show that the impact is varying and, for some markets (or events), the effects are positive and statistically significant, and this latter evidence contradicts perfect anticipation.

Individual Industries Reaction

[TABLE 5 HERE]

We now examine hypothesis (iii). We evaluate the price impact of the announcement at an industry-level. We compute industry CARs for 32 individual industries. For each industry we compute the cumulative cross-market average abnormal return. Our primary interest is to examine whether those industries that were a priori identified as directly gaining from the organization of the event, did observe more positive significant abnormal returns. Table 5 shows the announcement date ARs and the announcement date to next-day CARs for seven industries: Beverages, Construction, Leisure and Tourism, Media, Retail, Communications and Transportation. ${ }^{35}$ The last row of each panel shows the grand mean (across all industries). Panels A to $G$ contain the results for each event category.

Let's start with the grand mean abnormal return. Overall the results are similar to those in table 4: the effect is economically and statistically insignificant. ${ }^{36}$ As highlighted above, there seems to be a positive effect associated with the announcements of Specialized Exhibitions $(+0.5 \%)$. Additionally, the Winter Olympic Games show now a negative effect $(-1.0 \%)$. These results are statistically significant for the constant-mean residuals.

\footnotetext{
${ }^{35}$ Results for the other industries are not reported here to save space.

36 The aggregate values shown at the bottom of table 5 are equally-weighted averages of industry indices. The comparison of these equally-weighted values with the value-weighted averages reported in table 4, show that market weights do not drive the results.
} 
When we examine the individual industry abnormal returns, we fail to find consistent positive returns for the selected industries and, in most cases, the effects are small and not statistically different from zero. We observe (marginally) positive effects for the following industries:

- Communications (+0.7\%) regarding the World Exhibitions;

- Retail (+0.9\%) regarding the World Football Cups;

- Construction (+1.2\%) regarding the Summer Olympic Games;

- Media (0.6\%) for the European Capitals of Culture.

Yet we also find significant negative effects for a couple of industries. These are:

- Media (-1.7\%) regarding the Winter Olympic Games;

- Transportation (-2.1\%) regarding the European Football Cups.

These results are inconsistent with value-maximization theories because we fail to observe a positive significant effect for industries that a priori would benefit from the event. In any case, as above, results could reflect that these effects have already been anticipated by investors.

The results discussed in this and in the previous sections are not consistent with sentiment arguments because we do not observe a general positive effect that would reflect the joy associated with the nomination. Yet it can be argued that the sentiment effect will be more strongly reflected if the country is not nominated. Prices would reflect misery not joy. The next section examines the market impact felt by the losing countries.

\subsubsection{Losing Countries}

[TABLE 6 HERE]

We now shift to the impact of the announcement on the losing countries stock market prices. Hypothesis (ii) was that the announcement of the nomination would affect negatively the losing country stock market. This result would indicate that, prior to the 
announcement, market expectations included the likelihood country could win and benefit from the organization of the event. When the country loses, prices adjust downwards. Alternatively, a negative reaction could be merely associated with sentimental failure.

Table 6 shows the aggregate stock market effects for losers. Our sub-sample includes only those countries for which there was information regarding the losing candidates. Because of that, we had to exclude some of the World and all the European Football Cups. We also excluded the Specialized Exhibitions and the European Capitals of Culture because these were single candidacies-events. Further we excluded some losers for which market price information was not available. The final sub-sample comprises thus fifteen announcements (5 Olympic Summer Games, 5 Olympic Winter Games, 1 World Football Cup and 4 World Exhibitions.

We do not find a statistical significant negative market reaction as the partial anticipation or sentiment arguments would predict. On the contrary, for the specific case of the World Exhibitions we even observe a couple of positive CARs. Overall results are consistent with perfect anticipation.

\subsubsection{Summary of Abnormal Performance}

The bulk of the evidence so far is consistent with the rational expectations hypothesis or full anticipation. As observed above, the rational expectations hypothesis admits that such announcements will not affect the market value of listed firms because these news would imply no change in investment opportunities. The announcements would simply label anticipated growth opportunities. The results of the individual market analysis show a wide variation in the price impact observed. Below, we investigate whether between the variation in impact (across markets and events) is systematically related to factors such as economy-wide differential benefits or partial anticipation. 


\subsection{Cross-sectional analysis}

\subsubsection{Variables}

We evaluate the relation between the observed abnormal performance and a set of event, market and industry attributes as proposed by the empirical specification in (7). Abnormal returns are constant-mean adjusted returns. Table A.3 in appendix presents descriptive information for the variables of interest included in the cross-sectional analysis. The data shown are the mean, median, minimum, maximum and standard deviation of some characteristics of the events (relative size, lag and differential in votes received by the winning country in excess of the other final candidate), in aggregate and for each category or type of event. The table refers to a subset (32) of the events analyzed above for which information was available. These are 6 Summer Olympic Games, 8 Winter Olympic Games, 1 World Football Cup, 10 World Exhibitions and 7 Specialized Exhibitions.

The average mega-event has an investment of around 1\% of the country GNP, is announced 6 years in advance, and gets 56\% votes more than the losing country in the last round of voting.

On average, mega-events involve an investment of $1.24 \%$ of the host country GDP. Yet the median event is much smaller, of a magnitude of $0.17 \%$ of the host country GDP. The standard deviation is $1.74 \%$ and ranges from $0.002 \%$ (the 1980 Specialized Exhibition in Canada) to a maximum of 10.56\% (the 1992 Summer Olympic Games in Spain). When we split the sample into groups according to the type of event, we observe that the most important type of event are the Summer Olympic Games, that show an average (median) relative size of 3.3\% (1.7\%), followed by the Olympic Winter Games and the World Exhibitions that register the same average of 1.1\%. Specialized Exhibitions show the lowest percentages with an average of less than $0.1 \%$. On aggregate, and for any type of event analyzed, there seems to be no positive or negative 
deterministic trend over time in the relative amounts invested (even if increasing in absolute terms). ${ }^{37}$

The average (median) event is held 69 (71) months after its announcement and ranges between 1 (again the 1980 Specialized Exhibition in Canada) and 10 years (and again the 1992 Summer Olympic Games in Spain). ${ }^{38}$ Specialized Exhibitions take on average 49 months to be completed, against an average of 78, 69 and 76 months respectively for the Summer Olympic Games, the Winter Olympic Games and the World Exhibitions. The results suggest a positive relation between the size of the event and the time it takes to develop (and therefore the need to be announced in advance): this is the case for the 1992 Summer Olympic Games in Spain, whose investment amounted to $10.56 \%$ of GNP and was announced 10 years in advance. The correlation coefficient between the two variables is positive (18.6\%) but not statistically significant.

The average (median) percent of votes received by the winning country in excess of the other final candidate just before the outcome of the bidding process is revealed is $56 \%(39 \%)$. This result suggests that the outcome of these biddings is largely anticipated. In fact, this is the case for the Specialized Exhibitions for which, in all cases, there was only a single candidacy. As for the World Exhibitions, only the four more recent ones were competitive biddings. This is not the case for other events for which the bidding process is rather competitive like the Olympic Games and the Football Cups. The information regarding the voting rounds is only publicly available for the Olympic Games, the World Exhibitions and, very recently, also for the World Football Cups. The Olympic Games seem to be the most highly competitive biddings: the average (median) difference in votes between the winning and losing countries in the last round is respectively $28.8 \%$ and $32.7 \%$ (20.3\% and $27.5 \%$ ) for the Winter and Summer Games with a minimum of 2.3\% (2000 Summer Olympic Games in Australia).

37 "Beijing's Olympics-related spending of around $\$ 35$ billion, they calculated, would make up more than $43 \%$ of the total for all the games, including Beijing's, since Montreal's in 1976”, The Economist, March 1, 2007.

38 World Football Cups are announced 6 years in advance while European Football Cups were traditionally announced 4 years in advance but, in the more recent years, the announcement has been made earlier (about 5 years in advance). 
The average (median) difference in votes for the 5 World Football Cups, for which voting results have been made publicly available, is $34.7 \%(26.3 \%)$ with a minimum of $4.3 \%$ for the 2006 Cup in Germany. ${ }^{39}$ As for the World Exhibitions, the average (median) difference in votes is $66.9 \%(100 \%) .^{40}$

To save space we do not report here the statistics for the control variables used in the analysis. These include, at the market-level, the variable LIQ that proxies for differences in the role of the stock market across countries, and the indicator variables for economic activity, REC and EXP; at the industry-level, the variable REP is meant to capture the importance of a particular industry in total market capitalization. On average, stock markets represent $34 \%$ of GNP. Out of the total announcements only $9.4 \%$ occurred in recessions, while $37.5 \%$ occurred in expansions. This asymmetry is surprising given that in most cases, as we have seen above, the announcements of the nominations occur regularly to allow enough time for the organization of the event and, in some instances, for the development of the required infrastructures to host the event. It is thus very unlikely that the selection committee times the announcement, and the result must be either spurious or reflecting above-average economic performance over the sample period. Finally the average (median) value for REP is 3.8\% (1.9\%) ranging from near zero to $49 \%$.

\subsubsection{GLS estimates}

We regress cumulative abnormal returns $(\mathrm{CAR}[0,1])$ against the set of variables described in the previous section. Table 7 shows the estimated coefficients of the industry fixed effects regressions for two specifications (with and without the variable REP). We use a total of 699/701 pooled industry observations regarding 32 events.

\footnotetext{
39 This was a very tight victory: Germany secured 12 out of the 23 votes against the 12 received by South Africa (the other candidate in the final round).

40 The minimum was $2.4 \%$ for the 2000 World Exhibition: Germany secured 21 out the 41 votes against the 20 received by Canada.
} 
[TABLE 7 HERE]

The regressions show an adjusted R-square of $19 \%$ and estimates are similar for the two specifications. We find statistically significant coefficients for the independent variables $L A G, V O T$ and REP as well as for the two dummies D_WSG and D_WE.

As for the variable $L A G$, the coefficient is economically and statistically significant at the $1 \%$ level. Consistent with the investors' myopia hypothesis, the reaction to the announcement is smaller the larger the lag between the announcement and the realization of the event. For each further month, the CAR declines by $0.01 \%$.

The coefficient associated with the variable VOT is also very significant (at $1 \%$ level) and is consistent with investors partially anticipating the outcome of the bidding process. The more competitive the voting process (i.e., the smaller the difference in votes between the winning and the losing candidates), the larger the surprise and the greater the market impact. For a decline of $10 \%$ in the difference between the percentage of votes for winning and losing bidders, the CAR increases $0.23 \%$.

The coefficient of the control variable REP is significant at a $5 \%$ level. This positive relation between industry market weight and price impact could reflect awareness. If the industry is well-represented, investors will be more inclined to believe that mega-event news will affect the companies belonging to that industry.

The results for the OLS regressions using market (instead of industry) CARs are weak. The signs of the parameters are the same but the estimates lack statistical significance. This could directly stem from small sample size (32 events, 23 degrees of freedom).

\subsubsection{Summary}

The estimates of the cross-sectional regressions results confirm that abnormal returns are lower when the outcome is predictable and the larger the time-span between the announcement and the realization of the event. No general statement can be made regarding the economic merit of hosting mega-events but the evidence suggests that 
investors react as if some countries benefit from the organization of some mega-events such as the World Exhibitions.

\subsection{Partial anticipation}

\subsubsection{Partial anticipation I}

To evaluate the role of partial anticipation we test the model specification in (8). We pool the CARs for winners and losers. Our sample comprises 39 observations (24 winners and 15 losers).

\section{[TABLE 8 HERE]}

Panel A of Table 8 gives the results. The parameter associated with the prior probability of winning is negative (but not statistically significant). As for the parameter associated with the dummy for the nomination, we observed a positive and statistically significant estimate. The fit of the regression is poor but the evidence suggests that the effects are consistent with the rational predictions of the model proposed in Appendix B:

- losers register, on average, negative price impacts and the magnitude of the effect is associated with their priors of winning, and

- winners register, on average, positive price impacts; the magnitude of the effect is positively (negatively) related with the degree of surprise (anticipation) in the nomination news.

The evidence is not consistent with behavioral arguments. The sign of the intercept estimate is against the prediction (positive instead of negative) and not statistically different from zero.

We also run the regression with a balanced sample, including only those events for which we had information regarding the winning and for the losing bidders., i.e., we only (14 events, 28 observations -14 winners and 14 losers). The results are inconclusive. 


\subsubsection{Partial anticipation II}

We now turn to the alternative specification model of partial anticipation in (13). This specification uses a more refined proxy of the degree of surprise (anticipation) in the announcement news, using the information in all the successive rounds of voting.

\section{[TABLE 9 HERE]}

The regression results are shown in table 9. As for the previous model we estimate the model with unbalanced and balanced samples (panels A and B, respectively). To evaluate the effects for the winning and losing countries we perform a series of linear tests of the estimated parameters.

The fit of the model is good and similar for the unbalanced and balanced samples (adjusted R-square of 46\% and 60\%, respectively). We comment upon Panel A given that both panels show very similar results .

Overall the estimated parameters are in line with the rational predictions. We observe that:

- (1) when the outcome of the bidding process contains little or no news (in other words, there is partial or no surprise) there is no significant market reaction for the losers: Intercept+PS $(-0.32 \%)$ and Intercept $(0.54 \%)$ are not statistically significant. For the winning countries, the effect is negative (Intercept $+D=-0.68 \%$ ) and significant at the $10 \%$ level, if no surprise, and negative but not statistically significant if partial surprise (Intercept $+P S+D+D * P S=-0.89 \%)$.

- (2) when the outcome of the bidding process is a total surprise, the market reaction is negative and statistically significant for losers (Intercept+TS=-3.31\%). For the nominated countries we observe a very significant positive reaction $\left(\right.$ Intercept $\left.t+T S+D^{*} T S=+4.96 \%\right)$ We reject the null that the effects are the same for partial or total surprises. 
- (3) the results in (1) and (2) are generally inconsistent with sentiment arguments; further when we test for an asymmetric effect, we observe that, even when we control for partial anticipation, there are no stronger negative effects for losers.

\subsubsection{Summary}

The results of the partial anticipation models show that, when we control for prior expectations, the announcement of mega-events is associated with a positive market reaction in the nominated country and a negative reaction in the losing country. The greater the surprise, the greater the positive (negative) impact of the nomination news for the winning (losing) country.

\section{Conclusions}

This paper investigates the impact of international sporting and cultural events on national stock markets. We study market reaction to the announcement of the selected country hosting the Summer and Winter Olympic Games, the World Football Cup, the European Football Cup and World and Specialized Exhibitions. Using a cross-section of 81 events, we find that the abnormal returns measured at the announcement date are not consistently different from zero. When we look at particular industries, we find no evidence supporting that industries, that a priori were more likely to extract direct benefits from the event, observe stronger effects. We also find insignificant CARs for losing bidders. Given that for most of the events we study, the outcome is partially anticipated by investors, the market reaction around the announcement date does not seem to accurately measure the perceived economic impact of these events. In fact, when we control for the prior expectations upon the outcome of the voting, the announcement of mega-events is associated with a positive market reaction in the nominated country and a negative reaction in the losing country. Overall we interpret our findings as supportive of rational asset pricing and partial anticipation: when the 
announcement news are total surprises, market reaction is significant, positive for winners and negative for losers, reflecting that investors evaluate these mega-events announcements as positive news.

Our main results seem to hold for different definitions of abnormal performance and using a battery of tests to assess statistical significance and alternative empirical specifications to control for anticipation.

The market reaction we observe seems to reflect only a part of the overall perceived economic benefit of these mega-events. It is thus not correct to extrapolate these results to judge the economic merit of hosting these mega-events. The evidence suggests further that the economic benefits of hosting these mega-events vary across markets and events. The main finding of our study is that part of the variation in market reaction is associated with the degree of anticipation of the outcome of the bidding process. Further work is required to establish the other determinants of the observed cross-sectional variation in market reaction. 


\section{Appendix A. Typology of Events}

\section{THE OLYMPIC GAMES}

\section{www.olympic.org}

The Olympic Games is an international multi-sport event comprised of summer and winter events. Since 1994, each season's games have been held every four years, two years apart. The most recent Summer Olympics were the 2004 Games in Athens, Greece and the most recent Winter Olympics were the 2006 Games in Turin, Italy.

The host selection process is a highly competitive procedure. The process consists of successive rounds of voting. In every round candidates with the least votes are left behind. If no candidate secures votes in excess of $50 \%$, there are repetitive rounds until two candidates remain. In the last round of two, the country with more votes win.

\section{WORLD FOOTBALL CUPS}

\section{www.fifa.com}

The World Cup is organized by FIFA- Fedération Internationale de Football Association. The World Cup is held every four years. Nations all over the world compete in regional qualifying matches for the 32 places in the final tournament. Places are awarded to each region based on the number and quality of national teams in the area (ex: ELO ratings). Up to 1994, the finals were played in Europe and Latin America. Of the last 4 tournaments 2 were organized outside its traditional regions, in particular, in the US and in Japan/Korea. The last World Football Cup was held in Germany in 2006.

The decision on the country organizer is made upon several rounds of voting by members (regional football confederations) of the venue selection committee. The voting procedure is the following: voting will take place in successive rounds until one candidate receives a majority of those voting. If no candidate city achieves a majority in the first round, the candidate with the fewest votes drops out of the running, and the members vote again on the remaining candidates.

\section{EUROPEAN FOOTBALL CUPS}

www.uefa.com

European Football Cups are held every 4 years. The first European Nations' Cup, now known as the UEFA European Championship, was held in 1958. The bid process for staging UEFA 
EURO has been changing over time. In recent years the process involves an initial pre-selection of the potential bidders followed by the submission of initial bid dossiers by candidates. The final decision on the host of UEFA EURO is taken by UEFA Executive Committee. The last European Football Cup was held in Portugal in 2004.

\section{WORLD EXHIBITIONS AND SPECIALIZED EXHIBITIONS}

\section{www.bie-paris.org}

World (Universal or International) Exhibitions are held every five years. From having been exhibitions of state-of-the-art technological achievement, they are now broad national manifestations where the participating countries present themselves in their entirety. The rules are set by the Bureau International of World Exposition (BIE). Potential host nations apply to the BIE to hold a BIE-sanctioned Expo to celebrate some special event or to represent a concept or theme of their choosing. Under the more recent protocol (1988) there are two types of exposition - "registered" and "recognized". The registered expos are to be held every 5 years starting in 2010 In between the "registered expos", there will be one "recognized" exposition. The last World Exhibition was held in Aichi (Japan) in 2005.

Specialized expositions are also supervised by BIE but unlike World expositions, there was no set time between specialized expositions. The last Specialized Exhibition was held in Rostock (Germany) in 2003.

\section{EUROPEAN CAPITALS OF CULTURE}

http://ec.europa.eu/culture/eac/other actions/cap europ/cap eu en.html

The European City of Culture project was launched in 1985. The European Cities of Culture have been chosen until 2004, on an intergovernmental basis. Since then, the European Capitals of Culture are designated each year by the Council of Ministers of the EU, on the basis of the view of a selection panel${ }^{41}$. In 2006, Patras (Greece) was the selected city.

41 The selection procedure is laid down in Decision 1419/1999/CE amended by Decision 649/2005/CE. This Decision sets out a chronological list of Member States entitling them to host the event in turn. It defines as well the criteria the cities have to comply with to be designated as European Capital of Culture. Each Member State is invited to submit its application for one or more cities at least four years in advance. 


\section{Appendix B. A model of market impact of partially anticipated events}

This appendix presents a simple model of partial anticipation that generates a set of hypotheses tested in our study. The model we propose is built upon the models proposed by Malatesta and Thompson (1985) and Edmans, García and Norli (2007).

As in Malatesta and Thomson (1985), we consider that investors partially anticipate the likelihood that a particular country hosts one or several international sporting or cultural events. Let's denote $p_{i}$ as the probability of country $i$ hosting the event. Before the nominated host country is announced, the anticipated economic impact of the event is already reflected in the market valuations of the bidding countries. The economic impact of a particular event (its net present value) for candidate country listed firms is denoted by $N P V^{42}$ If country $j$ is chosen to host the contest, the (positive) market price effect at the date of announcement is given by $\left(1-p_{j}\right) \times N P V_{j}$. The observed market impact is thus a biased estimate of the true economic effect and is inversely related to the prior probability of winning. As for the market impact of the candidate countries whose bids were rejected, the loser countries, we should observe a negative market effect following the announcement, and, in absolute terms, positively related with the prior probability of winning. If we focus on the two countries in the last round of the voting process, when the final outcome is announced, the market price effect for the losing country $l$ is given by $-p_{l} N P V_{l}$ that equals $-\left(1-p_{j}\right) N P V_{l}$.

The potential benefits brought by the organization event are likely to be different from country to country (NPV varies across bidding candidates) and consequently the absolute magnitude of the stock market effects to winners and losers can differ substantially. As such, a priori, asymmetric effects are expected for the winning and losing countries.

\footnotetext{
42 Any interaction between the implementation of this project and the likelihood of future projects is ignored. For example, if a particular country is not nominated,, the probability of being chosen to host the same or similar events in the future may decrease - for example, European countries host the European Cities of Culture in turn - or increase - a country may be chosen to host the World Football Cup after successfully organizing an European Football Cup.
} 
In assessing the probability of winning (loosing), investors may consider the degree of competitiveness of the contest, whether the country is considered to be a front runner in advance and the initial rounds of the voting (that are publicized before the final outcome is realized). Our empirical model in section 4 accommodates some of these features.

At the day of the announcement, two possible outcomes may result. Either the country wins the organization of the event or looses. Let's denote $V W$ as the market valuation of a particular country at time $O$ if it hosts the event and VL its market valuation otherwise. Market valuation just before the event is announced $(t=-1)$ for a candidate country is thus given by:

$$
V_{i-1}=\frac{E\left(V_{i 0}\right)}{1+E\left(R_{i}\right)}=\frac{p_{i} V W_{i}+\left(1-p_{i}\right) V L_{i}}{1+E\left(R_{i}\right)} \quad(A-1)
$$

Given that

$$
V W_{i}=V L_{i}+N P V_{i}
$$

(A1) can be rewritten as:

$$
V_{i-1}=\frac{V L_{i}+p_{i} N P V_{i}}{1+E\left(R_{i}\right)}(A-2)
$$

Abnormal returns at the date of the announcement can be computed as:

$$
A R_{i}=\frac{1+R_{i}}{1+E\left(R_{i}\right)}-1 \quad(A-3)
$$


where

$$
R_{i}=\frac{V_{i 0}}{V_{i-1}}-1
$$

and $E\left(R_{i}\right)$ is the company's expected return for a given return generating process.

For the winning country $j, V_{0 j}=V W_{j}$, and abnormal returns are thus given by:

$$
\begin{aligned}
A R_{j} & =\frac{V W_{j} / V_{j_{-1}}}{1+E\left(R_{j}\right)}-1 \\
& =\frac{V W_{j} /\left[p_{j} V W_{j}+\left(1-p_{j}\right) V L_{j}\right] /\left(1+E\left(R_{j}\right)\right)}{1+E\left(R_{j}\right)}-1 \\
= & \frac{V W_{j}}{p_{j} V W_{j}+\left(1-p_{j}\right) V L_{j}}-1 \\
= & \frac{V L_{j}+N P V_{j}}{V L_{j}+p_{j} N P V_{j}}-1
\end{aligned}
$$

that can be rewritten as 


$$
\begin{aligned}
A R_{j} & =\frac{V L_{j}+p_{j} N P V_{j}+\left(1-p_{j}\right) N P V_{j}}{V L_{j}+p_{j} N P V_{j}}-1 \\
& =1+\frac{\left(1-p_{j}\right) N P V_{j}}{V L_{j}+p_{j} N P V_{j}}-1 \\
& =\frac{\left(\mathbf{1}-\boldsymbol{p}_{\boldsymbol{j}}\right) \boldsymbol{N P V _ { j }}}{\boldsymbol{V}_{\boldsymbol{j}_{-1}}\left(\mathbf{1}+\boldsymbol{E}\left(\boldsymbol{R}_{\boldsymbol{j}}\right)\right)}(A-4)
\end{aligned}
$$

For the losing country $l, V_{0 l}=V L_{l}$, and abnormal returns are given by:

$$
A R_{l}=\frac{V L_{l}}{V L_{l}+p_{l} N P V_{l}}-1
$$

that can be rewritten as,

$$
\begin{aligned}
& =\frac{V L_{l}+p_{l} N P V_{l}-p_{l} N P V_{l}}{V L_{l}+p_{l} N P V_{l}}-1 \\
& =1-\frac{p_{l} N P V_{l}}{V_{l-1}\left(1+E\left(R_{l}\right)\right)}-1 \\
& =\frac{-p_{l} N P V_{l}}{V_{l-1}\left(1+E\left(R_{l}\right)\right)} \\
& =\frac{-\left(\mathbf{1}-\boldsymbol{p}_{\boldsymbol{j}}\right) \mathbf{N P V _ { l }}}{\boldsymbol{V}_{l-1}\left(\mathbf{1}+\boldsymbol{E}\left(\boldsymbol{R}_{l}\right)\right)} \quad(A-5)
\end{aligned}
$$




\section{References}

Acharya, S., 1993, "Value of latent information: Alternative event study methods", Journal of Finance, Vol. 48, pp. 363-385.

Akhigbe, A., J. Madura and A.M. Whyte, 2004, "Partial anticipation and the gains to bank mergers", Journal of Financial Services Research, 26, pp. 55-71.

Baade, R.A. and V.A. Matheson, 2004, "The quest for the cup: assessing the economic impact of the World Cup”, Regional Studies, Vol. 38.4 (June), pp. 343-354.

Blose, L.E. and J.C.P. Shieh, 1997, “Tobin's Q-ratio and market reaction to capital investment announcements", Financial Review, Vol. 32, pp. 449-476.

Boehmer, E., J. Musumeci, and A. Poulsen, A., 1991, "Event study methodology under conditions of events induced variance", Journal of Financial Economics, Vol.30, pp. 253272.

Brown, S., and J. Warner, 1980, "Measuring security price performance", Journal of Financial Economics, Vol. 8, pp. 205-258.

Brown, S. and J. Warner, 1985, "Using daily stock returns: the case of event studies", Journal of Financial Economics, Vol.14, pp. 3-31.

Burton, B., A. Lonie and D. Power, 1999, "The stock market reaction to investment announcement: The case of individual capital expenditure projects", Journal of Business Finance \& Accounting, Vol. 26, June/July, pp. 681-708.

Corrado, C.J., 1989, "A non-parametric test for abnormal security price performance in event studies”, Journal of Financial Economics, Vol. 23, pp. 385-395.

Dimson, E. and M. Mussavian, 1998, "Professional forum: A brief history of market efficiency", European Financial Management, Vol. 4, pp. 91-103.

Dwyer, L., P. Forsyth and R. Spurr, 2005, "Estimating the impacts of special events on an economy", Journal of Travel Research, Vol. 43 (May), pp. 351-359.

Edmans, A., D. García and Ø. Norli, 2007, "Sports sentiments and stock returns", Journal of Finance, forthcoming.

Fama, E., 1965. "Random walks in stock market prices", Financial Analysts Journal September- October, pp. 55-59. 
Fama, E., 1991, “Efficient capital markets: II”, Journal of Finance, Vol. 46, pp. 1575-1617.

Fama, E., 1998, "Market efficiency, long-term returns, and behavioural finance", Journal of Financial Economics, Vol. 49, pp. 283-306.

Kothari, S.P. and J.B. Warner., 2005, "Econometrics of event studies" in Eckbo, B. Espen (ed.), Handbook of Corporate Finance: Empirical Corporate Finance, Handbooks in Finance Series, Elsevier/North-Holland.

Jones, E., J. Danbolt and I. Hirst, 2004, "Company investment announcements and the market value of the firm", European Journal of Finance, Vol. 10, pp. 437-452(16)

Malatesta, P.H. and Thompson, R., 1985, "Partially anticipated events: A model of stock price reactions with an application to corporate acquisitions", Journal of Financial Economics, Vol. 14, pp. 237-250.

Matheson, V., 2006, "Mega-Events: The effect of the world's biggest sporting events on local, regional, and national economies" International Association of Sport Economists Working Paper, 22.

Merton, R., 1987, "A simple model of capital market equilibrium with incomplete information", Journal of Finance, Vol. 42, 483-510.

Miller, M. and F. Modigliani, 1958, "The cost of capital, corporation finance and the theory of investment", The American Economic Review, Vol. 48, pp. 261-297.

Preto, M., 2004, "UEFA Euro 2004 championship: Impact on Portuguese equities", European Equity Research Reports, January.

Serra, A., 2004, "Event study tests: A brief survey”, Gestão.Org, Vol. 2, Sept./Dec.

Siegried, J. and A. Zimbalist, 2000, "The economics of sports facilities and their communities", Journal of Economic Perspectives, Vol. 14, pp. 95-114.

Titman, S., K.C.J. Wei, and F. Xie, 2004, Capital investments and stock returns, Journal of Financial and Quantitative Analysis, Vol. 39 (December), pp. 677-700.

Veraros, N., E. Kasimati and P. Dawson, 2004, "The 2004 Olympic Games announcement and its effect on the Athens and Milan stock exchanges", Applied Economics Letters, Vol. 11, pp. 749-753.

Vogt, S.C., 1997, "Cash flow and capital spending: evidence from capital expenditures announcement”, Financial Management, Vol. 26, pp. 44-57. 
Woolridge, J. and C. Snow, 1990, "Stock market reaction to strategic investment decisions", Strategic Management Journal, Vol. 11, pp. 353-363. 
Table 1

Events analyzed: hosting country and type of event

(number of events organized in parentheses)

\begin{tabular}{|c|c|c|c|c|c|c|c|}
\hline $\begin{array}{c}\text { Hosting Country } \\
\text { /Type of Event } \\
\text { (81) }\end{array}$ & $\begin{array}{c}\text { Summer } \\
\text { Olympic } \\
\text { Games } \\
(6)\end{array}$ & $\begin{array}{c}\text { Winter Olympic } \\
\text { Games } \\
(8)\end{array}$ & $\begin{array}{l}\text { World Football } \\
\text { Cups } \\
(6)\end{array}$ & $\begin{array}{c}\text { European Football } \\
\text { Cups } \\
(10)\end{array}$ & $\begin{array}{c}\text { World Exhibitions } \\
\text { (11) }\end{array}$ & $\begin{array}{l}\text { World Specialized } \\
\text { Exhibitions } \\
(10) \\
\end{array}$ & $\begin{array}{c}\text { European Capitals of } \\
\text { Culture } \\
(30)\end{array}$ \\
\hline \multicolumn{8}{|c|}{ EUROPE (58) } \\
\hline Germany (8) & & & 2006 & 1988 & 2000 & 1983 / 1993 / 2003 & 1988 / 1999 \\
\hline Austria (2) & & & & 2008 & & & 2003 \\
\hline Belgian (3) & & & & 2000 & & & $2000 / 2002$ \\
\hline Denmark (1) & & & & & & & 1996 \\
\hline Spain (5) & 1992 & & & & 1992 & & 1992 / $2000 / 2002$ \\
\hline Finland (1) & & & & & & & 2000 \\
\hline France (7) & & 1992 & 1998 & 1984 & & & 1989 / 1993 / $2000 / 2004$ \\
\hline Greece (3) & 2004 & & & & & & 1997 / 2006 \\
\hline Netherlands (5) & & & & 2000 & & 1982 / 2002 & 1987 / 2001 \\
\hline Ireland (2) & & & & & & & 1991 / 2005 \\
\hline Italy (7) & & 2006 & 1990 & 1980 & & 1992 & 1986 / $2000 / 2004$ \\
\hline Norway (2) & & 1994 & & & & & 2000 \\
\hline Poland (1) & & & & & & & 2000 \\
\hline Portugal (3) & & & & 2004 & 1998 & & 2001 \\
\hline United Kingdom (4) & & & & 1996 & & 1984 & $1990 / 2008$ \\
\hline Czech Republic (1) & & & & & & & 2000 \\
\hline Sweden (2) & & & & 1992 & & & 1998 \\
\hline Switzerland (1) & & & & 2008 & & & \\
\hline \multicolumn{8}{|c|}{ NORTH AMERICA (11) } \\
\hline Canada (4) & & $1988 / 2010$ & & & 1986 & 1980 & \\
\hline USA (7) & 1984 / 1996 & $1980 / 2002$ & 1994 & & $1982 / 1984$ & & \\
\hline \multicolumn{8}{|c|}{ ASIA (10) } \\
\hline Japan (5) & & 1998 & 2002 & & $1985 / 2005$ & 1990 & \\
\hline South Korea (2) & & & 2002 & & 1993 & & \\
\hline China (3) & 2008 & & & & 2010 & 1999 & \\
\hline \multicolumn{8}{|c|}{ OCEANY (2) } \\
\hline Australia (2) & 2000 & & & & & 1988 & \\
\hline
\end{tabular}


Table 2

Events analyzed: losing candidacies

(number of bids in parentheses)

\begin{tabular}{|c|c|c|c|c|}
\hline $\begin{array}{l}\text { Losing Country/ Type } \\
\text { of Event }\end{array}$ & $\begin{array}{l}\text { Summer Olympic Games } \\
\text { (13) }\end{array}$ & $\begin{array}{l}\text { Winter Olympic Games } \\
\qquad(13)\end{array}$ & $\begin{array}{l}\text { World Football Cup } \\
\qquad(2)\end{array}$ & $\begin{array}{l}\text { World Exhibitions } \\
(6)\end{array}$ \\
\hline \multicolumn{5}{|c|}{ EUROPE (19) } \\
\hline Germany (1) & 2000 & & & \\
\hline Austria (1) & & 2010 & & \\
\hline France (2) & 1992 / 2008 & & & \\
\hline Greece (N=1) & 1996 & & & \\
\hline Italy (2) & 2004 & 1988 & & \\
\hline Norway (1) & & 1992 & & \\
\hline United Kingdom (2) & 2000 & & 2006 & \\
\hline Russia (1) & & & & 2010 \\
\hline \multicolumn{5}{|c|}{$\begin{array}{c}1992 \text { / } 1994 \text { / } 1998 \text { / } \\
2002\end{array}$} \\
\hline Switzerland (2) & & & & \\
\hline \multicolumn{5}{|l|}{$\begin{array}{l}\text { Switzerland (2) } \\
\text { Turkey (1) }\end{array}$} \\
\hline \multicolumn{5}{|c|}{ NORTH AMERICA (9) } \\
\hline Canada (6) & 1996 / 2008 & 2002 & & $1998 / 2000 / 2005$ \\
\hline USA (2) & & 1994 / 1998 & & \\
\hline Mexico (1) & & & & 2010 \\
\hline \multicolumn{5}{|c|}{ ASIA (3) } \\
\hline Japan (1) & 1988 & & & \\
\hline South Korea (2) & & 2010 & & 2010 \\
\hline \multicolumn{5}{|c|}{ AFRICA (2) } \\
\hline South Africa (2) & 2004 & & 2006 & \\
\hline \multicolumn{5}{|c|}{ OCEANY (1) } \\
\hline Australia (1) & 1996 & & & \\
\hline
\end{tabular}


Table 3

Events analyzed: voting results for the winning and losing countries over the several rounds

PANEL A. Winning Countries

\begin{tabular}{|c|c|c|c|c|c|c|c|c|}
\hline \multirow{3}{*}{ Event } & \multirow{3}{*}{$\begin{array}{c}\text { Host } \\
\text { Country }\end{array}$} & \multicolumn{6}{|c|}{ Ranking } & \multirow{3}{*}{$\begin{array}{c}\text { Bid in } \\
\text { previous } \\
\text { event? }\end{array}$} \\
\hline & & $1^{\text {st }}$ & $2^{\text {nd }}$ & $3^{\text {rd }}$ & $4^{\text {th }}$ & $5^{\text {th }}$ & Always & \\
\hline & & Round & Round & Round & Round & Round & Leading? & \\
\hline \multicolumn{9}{|c|}{ Summer Olympic Games } \\
\hline 1984 & USA & \multicolumn{5}{|c|}{ single candidacy } & Yes & No \\
\hline 1992 & Spain & first & first & first & & & Yes & No \\
\hline 1996 & USA & second & third & first & first & first & No & No \\
\hline 2000 & Australia & second & second & second & first & & No & Yes \\
\hline 2004 & Greece & second & first & first & first & & No & Yes \\
\hline 2008 & China & first & first & & & & Yes & No \\
\hline \multicolumn{9}{|c|}{ Winter Olympic Games } \\
\hline 1980 & USA & \multicolumn{5}{|c|}{ single candidacy } & Yes & No \\
\hline 1988 & Canada & first & first & & & & Yes & No \\
\hline 1992 & France & second & first & first & first & first & Yes & No \\
\hline 1994 & Norway & first & second & first & & & No & Yes \\
\hline 1998 & Japan & first & first & first & first & & No & No \\
\hline 2002 & USA & first & & & & & Yes & Yes \\
\hline 2006 & Italy & first & & & & & Yes & No \\
\hline 2010 & Canada & second & first & & & & Yes & No \\
\hline \multicolumn{9}{|l|}{ World Exhibitions } \\
\hline 1998 & Portugal & first & & & & & Yes & No \\
\hline 2000 & Germany & first & & & & & Yes & No \\
\hline 2005 & Japan & first & & & & & Yes & No \\
\hline 2010 & China & first & first & first & first & & Yes & No \\
\hline \multicolumn{9}{|c|}{ World Football Cups } \\
\hline 1990 & Italy & first & & & & & Yes & No \\
\hline 1994 & USA & first & & & & & Yes & No \\
\hline 1998 & France & first & & & & & Yes & No \\
\hline 1998 & Japan & \multicolumn{5}{|c|}{ single candidacy } & Yes & No \\
\hline & Korea & \multicolumn{5}{|c|}{ single candidacy } & Yes & No \\
\hline 2006 & Germany & first & second & first & & & No & No \\
\hline
\end{tabular}


Table 3 (ctd.)

Events analyzed: voting results for the winning and losing countries over the several rounds

PANEL B. Losing Countries

\begin{tabular}{|c|c|c|c|c|c|c|c|c|}
\hline \multirow[b]{2}{*}{ Event } & \multirow[b]{2}{*}{$\begin{array}{l}\text { Losing } \\
\text { Country }\end{array}$} & \multicolumn{6}{|c|}{ Ranking } & \multirow{2}{*}{$\begin{array}{c}\text { Bid in } \\
\text { previous } \\
\text { event? }\end{array}$} \\
\hline & & $\begin{array}{c}1^{\text {st }} \\
\text { Round } \\
\end{array}$ & $\begin{array}{c}2^{\text {nd }} \\
\text { Round } \\
\end{array}$ & $\begin{array}{c}3^{\text {rd }} \\
\text { Round }\end{array}$ & $\begin{array}{c}4^{\text {th }} \\
\text { Round }\end{array}$ & $\begin{array}{c}5^{\text {th }} \\
\text { Round }\end{array}$ & $\begin{array}{c}\text { Ever } \\
\text { Leading? }\end{array}$ & \\
\hline \multicolumn{9}{|c|}{ Summer Olympic Games } \\
\hline 1988 & Japan & second & & & & & no & no \\
\hline 1992 & France & first & second & second & & & no & no \\
\hline 1996 & Greece & first & first & First & second & second & yes & no \\
\hline 2004 & Italy & second & second & second & second & & no & no \\
\hline 2008 & Canada & second & second & & & & no & no \\
\hline \multicolumn{9}{|c|}{ Winter Olympic Games } \\
\hline 1994 & Sweden & third & first & second & & & yes & yes \\
\hline 1998 & USA & fourth & second & second & second & & yes & no \\
\hline 2002 & Switzerland & second & & & & & no & no \\
\hline 2006 & Switzerland & second & & & & & no & yes \\
\hline 2010 & Korea & first & second & & & & no & no \\
\hline \multicolumn{9}{|l|}{ World Exhibitions } \\
\hline 1998 & Canada & second & & & & & no & no \\
\hline 2000 & Canada & second & & & & & no & yes \\
\hline 2005 & Canada & second & & & & & no & yes \\
\hline 2010 & Korea & second & second & second & second & & no & no \\
\hline \multicolumn{9}{|c|}{ World Football Cups } \\
\hline 2006 & South Africa & second & second & second & & & no & no \\
\hline
\end{tabular}




\section{Table 4}

Abnormal returns at and around the announcement date: winning countries

This table reports average abnormal returns (AR) at the announcement date and cumulative average abnormal returns (CAR) for several other event windows around the announcement day. Abnormal returns are constant-mean and risk-adjusted returns. Model parameters were estimated regressing market index returns on the world market index over the period $[-120,-20]$ in event time. $\theta_{1}$ and $\theta_{2}$ are the Brown and Warner $(1980,1985) t$-test statistics, without and with crude dependence adjustment. $\tau_{1}$ is the z-statistic for the sign test. ${ }^{a},{ }^{b}$ and ${ }^{c}$ denote statistical significance at the $1 \%, 5 \%$ and $10 \%$ levels for bilateral tests.

PANEL A. Summer Olympic Games

\begin{tabular}{cccccccccc}
\hline \multicolumn{1}{c}{ Market Model } & \multicolumn{5}{c}{ Constant-Mean Model countries } \\
\hline & {$[-1,1]$} & {$[\mathbf{0 , 0}]$} & {$[\mathbf{0 , 1}]$} & {$[\mathbf{0 , 5}]$} & {$[-\mathbf{1 , 1}]$} & {$[\mathbf{0 , 0}]$} & {$[\mathbf{0 , 1}]$} & {$[\mathbf{0 , 5}]$} \\
\hline CAR (\%) & $\mathbf{0 . 6 8 6 9}$ & $\mathbf{- 0 . 0 8 0 2}$ & $\mathbf{0 . 7 9 5 6}$ & $\mathbf{- 1 . 1 1 9 9}$ & $\mathbf{0 . 3 4 9 2}$ & $\mathbf{- 0 . 2 0 3 0}$ & $\mathbf{0 . 4 6 7 8}$ & $\mathbf{- 2 . 0 4 2 5}$ \\
$\boldsymbol{\theta}_{1}$ & $(0.477)$ & $(-0.167)$ & $(0.828)$ & $(-0.389)$ & $(0.232)$ & $(-0.405)$ & $(0.466)$ & $(-0.678)$ \\
$\boldsymbol{\theta}_{2}$ & $(0.465)$ & $(-0.163)$ & $(0.808)$ & $(-0.379)$ & $(0.228)$ & $(-0.397)$ & $(0.458)$ & $(-0.666)$ \\
\# Positive AR & 3 & 3 & 3 & 3 & 2 & 3 & 2 & 2 \\
$\tau_{1}$ & $(0.000)$ & $(0.000)$ & $(0.000)$ & $(0.000)$ & $(-0.816)$ & $(0.000)$ & $(-0.816)$ & $(-0.816)$ \\
\hline
\end{tabular}

PANEL B. Winter Olympic Games

\begin{tabular}{|c|c|c|c|c|c|c|c|c|}
\hline & \multicolumn{3}{|c|}{ Market Model } & \multicolumn{5}{|c|}{ Constant-Mean Model } \\
\hline & {$[-1,1]$} & {$[0,0]$} & {$[0,1]$} & {$[0,5]$} & {$[-1,1]$} & {$[0,0]$} & {$[0,1]$} & {$[0,5]$} \\
\hline CAR (\%) & -0.1475 & -0.2688 & -0.2315 & 0.1392 & -0.6561 & -0.4788 & -0.8302 & 0.0401 \\
\hline$\theta_{1}$ & $(-0.163)$ & $(-0.894)$ & $(-0.385)$ & $(0.077)$ & $(-0.573)$ & $(-1.255)$ & $(-1.088)$ & $(0.018)$ \\
\hline$\theta_{2}$ & $(-0.150)$ & $(-0.821)$ & $(-0.353)$ & $(0.071)$ & $(-0.598)$ & $(-1.310)$ & $(-1.136)$ & $(0.018)$ \\
\hline \# Positive AR & 4 & 2 & 3 & 3 & 4 & 3 & 3 & 3 \\
\hline$\tau_{1}$ & $(0.000)$ & $(-1.414)$ & $(-0.707)$ & $(-0.707)$ & $(0.000)$ & $(-0.707)$ & $(-0.707)$ & $(-0.707)$ \\
\hline
\end{tabular}


Table 4 (ctd.)

Abnormal returns at and around the announcement date

PANEL C. World Football Cups

6 countries

\begin{tabular}{ccccccccc}
\hline \multicolumn{3}{c}{ Market Model } & \multicolumn{7}{c}{ Constant-Mean Model } \\
\hline & {$[-1, \mathbf{1}]$} & {$[\mathbf{0 , 0}]$} & {$[\mathbf{0 , 1}]$} & {$[\mathbf{0 , 5}]$} & {$[-\mathbf{1 , 1}]$} & {$[\mathbf{0 , 0}]$} & {$[\mathbf{0 , 1}]$} & {$[\mathbf{0 , 5}]$} \\
\hline CAR (\%) & $\mathbf{- 0 . 2 9 3 7}$ & $\mathbf{- 0 . 0 2 4 8}$ & $\mathbf{- 0 . 2 0 2 7}$ & $\mathbf{- 0 . 8 0 6 3}$ & $\mathbf{- 0 . 3 3 2 8}$ & $\mathbf{- 0 . 1 6 3 5}$ & $\mathbf{- 0 . 0 7 0 6}$ & $\mathbf{- 0 . 7 3 0 6}$ \\
$\boldsymbol{\theta}_{1}$ & $(-0.239)$ & $(-0.060)$ & $(-0.247)$ & $(-0.328)$ & $(-0.243)$ & $(-0.358)$ & $(-0.077)$ & $(-0.267)$ \\
$\boldsymbol{\theta}_{2}$ & $(-0.237)$ & $(-0.060)$ & $(-0.245)$ & $(-0.325)$ & $(-0.227)$ & $(-0.335)$ & $(-0.072)$ & $(-0.249)$ \\
\# Positive & & & & & & & & \\
AR & 3 & 3 & 2 & 2 & 3 & 2 & 4 & 2 \\
$\tau_{1}$ & $(0.000)$ & $(0.000)$ & $(-0.816)$ & $(-0.816)$ & $(0.000)$ & $(-0.816)$ & $(0.816)$ & $(-0.816)$ \\
\hline
\end{tabular}

PANEL D. European Football Cups

\begin{tabular}{cccccccccc}
\hline \multicolumn{1}{c}{ Market Model } & \multicolumn{7}{c}{ Constant-Mean Model contries } \\
\hline & {$[-\mathbf{- 1 , 1}]$} & {$[\mathbf{0 , 0}]$} & {$[\mathbf{0 , 1}]$} & {$[\mathbf{0 , 5}]$} & {$[-\mathbf{1 , 1}]$} & {$[\mathbf{0 , 0}]$} & {$[\mathbf{0 , 1}]$} & {$[\mathbf{0 , 5}]$} \\
\hline CAR (\%) & $\mathbf{0 . 3 8 4 7}$ & $\mathbf{- 0 . 2 2 5 8}$ & $\mathbf{0 . 1 8 0 7}$ & $\mathbf{0 . 3 9 6 8}$ & $\mathbf{0 . 2 1 0 4}$ & $\mathbf{- 0 . 1 7 9 3}$ & $\mathbf{- 0 . 0 3 5 6}$ & $\mathbf{0 . 3 4 7 2}$ \\
$\boldsymbol{\theta}_{1}$ & $(0.457)$ & $(-0.804)$ & $(0.322)$ & $(0.236)$ & $(0.213)$ & $(-0.544)$ & $(-0.054)$ & $(0.176)$ \\
$\boldsymbol{\theta}_{2}$ & $(0.396)$ & $(-0.697)$ & $(0.279)$ & $(0.204)$ & $(0.190)$ & $(-0.485)$ & $(-0.048)$ & $(0.156)$ \\
$\#$ Positive & & & & & & & & \\
AR & 7 & 4 & 7 & 5 & 5 & 4 & 4 & 6 \\
$\tau_{1}$ & $(1.265)$ & $(-0.632)$ & $(1.265)$ & $(0.000)$ & $(0.000)$ & $(-0.632)$ & $(-0.632)$ & $(0.632)$ \\
\hline
\end{tabular}

PANEL E. World Exhibitions

\begin{tabular}{cccccccccc}
\hline \multicolumn{1}{c}{ Market Model } & \multicolumn{7}{c}{ Constant-Mean Model } & \\
\hline & {$[-1, \mathbf{1}]$} & {$[\mathbf{0 , 0}]$} & {$[\mathbf{0 , 1}]$} & {$[\mathbf{0 , 5}]$} & {$[\mathbf{- 1 , 1}]$} & {$[\mathbf{0 , 0}]$} & {$[\mathbf{0 , 1}]$} & {$[\mathbf{0 , 5}]$} \\
$\mathbf{C A R}(\mathbf{\%})$ & $\mathbf{- 0 . 6 1 0 8}$ & $\mathbf{- 0 . 2 4 2 3}$ & $\mathbf{- 0 . 4 5 9 6}$ & $\mathbf{- 0 . 3 4 4 7}$ & $\mathbf{- 0 . 4 1 8 0}$ & $\mathbf{- 0 . 1 3 2 5}$ & $\mathbf{- 0 . 3 4 8 4}$ & $\mathbf{- 0 . 4 6 1 8}$ \\
$\boldsymbol{\theta}_{1}$ & $(-0.683)$ & $(-0.812)$ & $(-0.771)$ & $(-0.193)$ & $(-0.439)$ & $(-0.417)$ & $(-0.548)$ & $(-0.242)$ \\
$\boldsymbol{\theta}_{2}$ & $(-0.689)$ & $(-0.820)$ & $(-0.778)$ & $(-0.195)$ & $(-0.460)$ & $(-0.438)$ & $(-0.575)$ & $(-0.254)$ \\
$\#$ Positive & & & & & & & & \\
AR & 3 & 3 & 4 & 4 & 5 & 4 & 5 & 4 \\
$\tau_{1}$ & $(-1.508)$ & $(-1.508)$ & $(-0.905)$ & $(-0.905)$ & $(-0.302)$ & $(-0.905)$ & $(-0.302)$ & $(-0.905)$ \\
\hline
\end{tabular}


Table 4 (ctd.)

Abnormal returns at and around the announcement date

PANEL F. Specialized Exhibitions

\begin{tabular}{ccccccccc}
\hline \multicolumn{3}{c}{ Market Model } & \multicolumn{7}{c}{ Constant-Mean Model } \\
\hline & {$[-1,1]$} & {$[\mathbf{0 , 0}]$} & {$[\mathbf{0 , 1}]$} & {$[\mathbf{0 , 5}]$} & {$[-\mathbf{1 , 1}]$} & {$[\mathbf{0 , 0}]$} & {$[\mathbf{0 , 1}]$} & {$[\mathbf{0 , 5}]$} \\
\hline CAR (\%) & $\mathbf{0 . 4 6 7 8}$ & $\mathbf{0 . 2 4 7 5}$ & $\mathbf{0 . 6 0 0 2}$ & $\mathbf{0 . 2 3 0 0}$ & $\mathbf{0 . 2 5 9 1}$ & $\mathbf{0 . 2 1 4 7}$ & $\mathbf{0 . 5 9 2 5}$ & $\mathbf{- 0 . 1 7 9 3}$ \\
$\boldsymbol{\theta}_{1}$ & $(0.589)$ & $(0.935)$ & $(1.134)$ & $(0.145)$ & $(0.307)$ & $(0.762)$ & $(1.052)$ & $(-$ \\
$\boldsymbol{\theta}_{2}$ & $(0.658)$ & $(1.045)$ & $(1.267)$ & $(0.162)$ & $(0.351)$ & $(0.872)$ & $(1.203)$ & $(-$ \\
\# Positive & & & & & & & & $0.121)$ \\
AR & 7 & 7 & 8 & 8 & 6 & 8 & 7 & 7 \\
$\tau_{1}$ & $(1.265)$ & $(1.265)$ & $(1.897)^{c}$ & $(1.897)^{c}$ & $(0.632)$ & $(1.897)^{c}$ & $(1.265)$ & $(1.265)$ \\
\hline
\end{tabular}

PANEL G. European Capitals of Culture

\begin{tabular}{ccccccccc}
\hline \multicolumn{1}{c}{ Market Model } & \multicolumn{7}{c}{ Constant-Mean Model countries } \\
\hline & {$[-1, \mathbf{1}]$} & {$[\mathbf{0 , 0}]$} & {$[\mathbf{0 , 1}]$} & {$[\mathbf{0 , 5}]$} & {$[-\mathbf{1 , 1}]$} & {$[\mathbf{0 , 0}]$} & {$[\mathbf{0 , 1}]$} & {$[\mathbf{0 , 5}]$} \\
\hline CAR (\%) & $\mathbf{- 0 . 6 0 6 7}$ & $\mathbf{- 0 . 1 6 9 5}$ & $\mathbf{- 0 . 1 4 0 1}$ & $\mathbf{- 0 . 4 2 9 9}$ & $\mathbf{- 0 . 9 4 5 5}$ & $\mathbf{- 0 . 1 9 8 8}$ & $\mathbf{- 0 . 1 9 6 8}$ & $\mathbf{- 0 . 5 4 5 5}$ \\
$\boldsymbol{\theta}_{1}$ & $(-1.114)$ & $(-0.933)$ & $(-0.386)$ & $(-0.395)$ & $(-1.607)$ & $(-1.013)$ & $(-0.502)$ & $(-0.463)$ \\
$\boldsymbol{\theta}_{2}$ & $(-0.838)$ & $(-0.702)$ & $(-0.290)$ & $(-0.297)$ & $(-1.106)$ & $(-0.698)$ & $(-0.345)$ & $(-0.319)$ \\
\# Positive & & & & & & & & \\
AR & 11 & 14 & 16 & 14 & 10 & 14 & 15 & 13 \\
$\tau_{1}$ & $(-1.461)$ & $(-0.365)$ & $(0.365)$ & $(-0.365)$ & $(-1.826)$ & $(-0.365)$ & $(0.000)$ & $(-0.730)$ \\
\hline
\end{tabular}


Table 5

Industry abnormal returns at and around the announcement date: winning countries

This table reports industry average abnormal returns (AR) at the announcement date, and day of the announcement and next day cumulative average abnormal returns (CAR). \# denotes the number of markets used to compute the industry average abnormal returns. Abnormal returns are constant-mean and risk-adjusted returns. Model parameters were estimated regressing market index returns on the world market index over the period $[-120,-20]$ in event time. The table shows the abnormal returns for the industries that a priori would benefit more from the event. The last row shows the global average AR and CAR across all industries (up to 32). In parentheses we report Brown and Warner $(1980,1985) t$-test statistics, without crude dependence adjustment. ${ }^{a},{ }^{b}$ and ${ }^{c}$ denote statistical significance at the $1 \%, 5 \%$ and $10 \%$ levels for bilateral tests.

PANEL A. Summer Olympic Games

\begin{tabular}{lcccc}
\hline & \multicolumn{2}{c}{ Market Model } & \multicolumn{2}{c}{ Constant-Mean Model } \\
\hline & {$[\mathbf{0 , 0}]$} & {$[\mathbf{0 , 1}]$} & {$[\mathbf{0 , 0}]$} & {$[\mathbf{0 , 1}]$} \\
\hline Beverages (\#5) & 0.254 & 1.244 & 0.422 & 2.686 \\
& $(0.263)$ & $(0.643)$ & $(0.394)$ & $(1.254)$ \\
Construction (\#6) & 0.098 & 0.118 & 0.074 & 1.192 \\
& $(0.154)$ & $(0.092)$ & $(0.474)$ & $(3.815)$ \\
Leisure and Tourism (\#4) & 0.377 & 0.146 & 0.112 & -0.487 \\
\multirow{2}{*}{ Media (\#5) } & $(0.819)$ & $(0.159)$ & $(0.191)$ & $(-0.416)$ \\
& 0.217 & 0.484 & 0.083 & 1.521 \\
Retail (\#3) & $(0.323)$ & $(0.360)$ & $(0.107)$ & $(0.980)$ \\
& -0.08 & -0.295 & -0.338 & -0.692 \\
Communications (\#4) & $(-0.185)$ & $(-0.341)$ & $(-0.457)$ & $(-0.467)$ \\
& 0.155 & 1.351 & 0.082 & 1.542 \\
Transportation (\#5) & $(0.397)$ & $(1.727)$ & $(0.127)$ & $(1.199)$ \\
& 0.302 & 0.304 & 0.009 & 1.093 \\
Global Average & $(0.544)$ & $(0.275)$ & $(0.012)$ & $(0.722)$ \\
\hline
\end{tabular}

PANel B. Winter Olympic Games

\begin{tabular}{lcccc}
\hline & \multicolumn{3}{c}{ Market Model } & \multicolumn{2}{c}{ Constant-Mean Model } \\
\hline & {$[\mathbf{0 , 0}]$} & {$[\mathbf{0 , 1}]$} & {$[\mathbf{0 , 0}]$} & {$[\mathbf{0 , 1}]$} \\
\hline \multirow{2}{*}{ Beverages (\#6) } & -0.009 & 0.409 & -0.689 & -0.797 \\
& $(-0.019)$ & $(0.439)$ & $(-1.105)$ & $(-0.639)$ \\
Construction (\#8) & -0.633 & 0.895 & -0.852 & 0.270 \\
& $(-1.284)$ & $(0.908)$ & $(-1.491)$ & $(0.236)$ \\
Leisure and Tourism (\#5) & 0.022 & -0.310 & -0.746 & -1.948 \\
& $(0.033)$ & $(-0.230)$ & $(-0.911)$ & $(-1.189)$ \\
Media (\#7) & -1.144 & -0.580 & 1.741 & -1.764 \\
& $(-2.410)$ & $(-0.612)$ & $(-2.870)^{a}$ & $(-1.454)$ \\
Retail (\#7) & 0.733 & 0.703 & 0.161 & -0.397 \\
\multirow{2}{*}{ Communications (\#6) } & $(1.642)$ & $(0.788)$ & $(0.279)$ & $(-0.344)$ \\
\multirow{2}{*}{ Transportation (\#7) } & -0.471 & -0.395 & -0.643 & -1.344 \\
& $(-1.147)$ & $(-0.481)$ & $(-1.113)$ & $(-1.164)$ \\
Global Average & 0.127 & -0.103 & -0.215 & -0.360 \\
& $(-1.147)$ & $(0.367)$ & $(-0.370)$ & $(-0.309)$ \\
\hline
\end{tabular}


Table 5 (ctd.)

Industry abnormal returns at and around the announcement date

PANEL C. World Football Cups

\begin{tabular}{lcccc}
\hline & \multicolumn{2}{c}{ Market Model } & \multicolumn{2}{c}{ Constant-Mean Model } \\
\hline \multirow{2}{*}{ Beverages (\#5) } & {$[\mathbf{0 , 0}]$} & {$[\mathbf{0 , 1}]$} & {$[\mathbf{0 , 0}$} & {$[\mathbf{0 , 1}]$} \\
\multirow{2}{*}{ Construction (\#6) } & -1.216 & -0.272 & -1.181 & -0.070 \\
& $(-1.520)$ & $(-0.170)$ & $(-1.371)$ & $(-0.040)$ \\
Leisure and Tourism (\#5) & -0.475 & -0.401 & -0.588 & -0.427 \\
& $(-1.309)$ & $(-0.553)$ & $(-1.172)$ & $(-0.425)$ \\
Media (\#4) & 0.778 & 0.877 & 0.529 & 1.036 \\
& $(0.777)$ & $(0.438)$ & $(0.444)$ & $(0.436)$ \\
Retail (\#5) & -0.111 & -0.479 & -0.099 & -0.208 \\
& $(-0.183)$ & $(-0.397)$ & $(-0.129)$ & $(-0.135)$ \\
Communications (\#5) & 0.909 & 1.626 & 0.717 & 1.364 \\
& $(1.676)$ & $(1.497)$ & $(1.017)$ & $(0.967)$ \\
Transportation (\#6) & 0.810 & 1.110 & 0.678 & 1.349 \\
& $(1.344)$ & $(0.920)$ & $(0.710)$ & $(0.707)$ \\
Global Average & 0.637 & -0.370 & 0.573 & -0.395 \\
& $(1.156)$ & $(-0.336)$ & $(0.908)$ & $(-0.313)$ \\
\hline
\end{tabular}

PANEL D. European Football Cups

\begin{tabular}{lcccc}
\hline & \multicolumn{2}{c}{ Market Model } & \multicolumn{2}{c}{ Constant-Mean Model } \\
\hline \multirow{2}{*}{ Beverages (\#5) } & {$[\mathbf{0 , 0}]$} & {$[\mathbf{0 , 1}]$} & {$[\mathbf{0 , 0}$} & {$[\mathbf{0 , 1}]$} \\
Construction (\#6) & 0.491 & 0.061 & 0.314 & 0.038 \\
& $(1.019)$ & $(0.064)$ & $(0.602)$ & $(0.037)$ \\
Leisure and Tourism (\#5) & 0.156 & 0.298 & 0.177 & 0.448 \\
& $(0.525)$ & $(0.503)$ & $(0.441)$ & $(0.558)$ \\
Media (\#4) & 0.464 & 1.197 & 0.377 & 1.258 \\
& $(0.486)$ & $(0.627)$ & $(0.369)$ & $(0.616)$ \\
Retail (\#5) & 0.097 & 0.356 & -0.168 & 0.216 \\
& $(0.176)$ & $(0.322)$ & $(-0.280)$ & $(0.180)$ \\
Communications (\#5) & -0.175 & -0.262 & -0.346 & -0.161 \\
& $(-0.392)$ & $(-0.294)$ & $(-0.654)$ & $(-0.152)$ \\
Transportation (\#6) & -0.496 & -0.470 & -0.717 & -0.565 \\
& $(-1.163)$ & $(-0.551)$ & $(-1.393)$ & $(-.549)$ \\
Global Average & -1.586 & -1.388 & -2.056 & -1.557 \\
& $(-1.970)$ & $(-0.862)$ & $(-2.370)$ & $(-0.897)$ \\
\hline
\end{tabular}


Table 5 (ctd.)

Industry abnormal returns at and around the announcement date

PANEL E. World Exhibitions

\begin{tabular}{lcccc}
\hline & \multicolumn{3}{c}{ Market Model } & \multicolumn{2}{c}{ Constant-Mean Model } \\
\hline \multirow{2}{*}{ Beverages (\#10) } & {$[\mathbf{0 , 0}]$} & {$[\mathbf{0 , 1}]$} & {$[\mathbf{0 , 0}$} & {$[\mathbf{0 , 1}]$} \\
\multirow{2}{*}{ Construction (\#11) } & -0.327 & -0.400 & -0.191 & -0.429 \\
& $(-0.618)$ & $(-0.378)$ & $(-0.344)$ & $(-0.376)$ \\
Leisure and Tourism (\#6) & 0.091 & 0.017 & 0.018 & -0.296 \\
& $(0.276)$ & $(0.026)$ & $(0.043)$ & $(-0.348)$ \\
Media (\#8) & 0.449 & 0.370 & 0.658 & 0.396 \\
& $(0.841)$ & $(0.346)$ & $(1.094)$ & $(0.329)$ \\
Retail (\#8) & 0.607 & 1.312 & 0.867 & 1.411 \\
& $(1.307)$ & $(1.412)$ & $(1.638)$ & $(1.333)$ \\
Communications (\#7) & 0.060 & 0.070 & -0.039 & -0.099 \\
& $(0.177)$ & $(0.103)$ & $(-0.088)$ & $(-0.113)$ \\
Transportation (\#9) & 0.709 & 0.641 & 0.733 & 0.748 \\
& $(1.739)$ & $(0.785)$ & $(1.467)$ & $(0.749)$ \\
Global Average & 0.194 & 0.704 & 0.099 & 0.215 \\
& $(0.512)$ & $(0.931)$ & $(0.203)$ & $(0.221)$ \\
\hline
\end{tabular}

PANEL F. Specialized Exhibitions

\begin{tabular}{lcccc}
\hline & \multicolumn{3}{l}{ Market Model } & \multicolumn{2}{c}{ Constant-Mean Model } \\
\hline \multirow{2}{*}{ Beverages (\#9) } & {$[\mathbf{0 , 0}]$} & {$[\mathbf{0 , 1 ]}$} & {$[\mathbf{0 , 0}]$} & {$[\mathbf{0 , 1 ]}$} \\
\multirow{2}{*}{ Construction (\#10) } & 0.516 & 0.665 & 0.749 & 1.037 \\
& $(0.969)$ & $(0.624)$ & $(1.231)$ & $(0.853)$ \\
Leisure and Tourism (\#3) & 0.058 & 0.313 & 0.155 & 0.797 \\
& $(0.176)$ & $(0.472)$ & $(0.397)$ & $(1.023)$ \\
Media (\#7) & -0.628 & 0.385 & -0.691 & 1.872 \\
& $(-0.713)$ & $(0.218)$ & $(-0.623)$ & $(0.844)$ \\
Retail (\#9) & -0.052 & -0.567 & 0.049 & -0.437 \\
& $(-0.133)$ & $(-0.730)$ & $(0.113)$ & $(-0.510)$ \\
Communications (\#7) & -0.509 & -0.843 & -0.401 & -0.420 \\
& $(-1.316)$ & $(-1.090)$ & $(-0.928)$ & $(-0.486)$ \\
Transportation (\#10) & -0.106 & -0.793 & 0.098 & -0.188 \\
& $(-0.267)$ & $(-1.004)$ & $(0.204)$ & $(-0.196)$ \\
\multirow{2}{*}{ Global Average } & -0.228 & 0.626 & -0.041 & 1.193 \\
& $(-0.531)$ & $(0.730)$ & $(-0.081)$ & $(1.178)$ \\
\hline
\end{tabular}


Table 5 (ctd.)

Industry abnormal returns at and around the announcement date

PANEL G. European Capitals of Culture

\begin{tabular}{lcccc}
\hline & \multicolumn{2}{c}{ Market Model } & \multicolumn{2}{c}{ Constant-Mean Model } \\
\hline \multirow{2}{*}{ Beverages (\#24) } & {$[\mathbf{0 , 0}]$} & {$[\mathbf{0 , 1}]$} & {$[\mathbf{0 , 0 ]}$} & {$[\mathbf{0 , 1}]$} \\
& -0.069 & 0.337 & -0.173 & 0.203 \\
Construction (\#30) & $(-0.200)$ & $(0.485)$ & $(-0.435)$ & $(0.255)$ \\
& -0.046 & 0.263 & -0.257 & 0.019 \\
Leisure and Tourism (\#15) & $(-0.229)$ & $(0.660)$ & $(-0.989)$ & $(0.036)$ \\
& -0.312 & -0.168 & -0.328 & -0.191 \\
Media (\#22) & $(-0.834)$ & $(-0.224)$ & $(-0.746)$ & $(-0.217)$ \\
& 0.615 & 0.754 & 0.541 & 0.643 \\
Retail (\#22) & $(1.830)$ & $(1.121)$ & $(1.505)$ & $(0.894)$ \\
& -0.291 & 0.077 & -0.259 & -0.259 \\
Communications (\#18) & $(-1.008)$ & $(0.133)$ & $(-0.785)$ & $(-0.785)$ \\
& 0.016 & 0.347 & -0.139 & 0.200 \\
Transportation (\#25) & $(0.055)$ & $(0.577)$ & $(-0.340)$ & $(0.244)$ \\
& 0.322 & 0.388 & 0.272 & 0.334 \\
\multirow{2}{*}{ Global Average } & $(0.972)$ & $(0.586)$ & $(0.739)$ & $(0.454)$ \\
\hline
\end{tabular}




\section{Table 6}

Abnormal returns at and around the announcement date: losing countries

This table reports average abnormal returns (AR) at the announcement date and cumulative average abnormal returns (CAR) for several other event windows around the announcement day. Abnormal returns are constant-mean and risk-adjusted returns. Model parameters were estimated regressing market index returns on the world market index over the period $[-120,-20]$ in event time. $\theta_{1}$ and $\theta_{2}$ are the Brown and Warner $(1980,1985) t$-test statistics, without and with crude dependence adjustment. $\tau_{1}$ is the z-statistic for the sign test. ${ }^{a},{ }^{b}$ and ${ }^{c}$ denote statistical significance at the $1 \%, 5 \%$ and $10 \%$ levels for bilateral tests.

PANEL A. Summer Olympic Games

\begin{tabular}{cccccccccc}
\hline \multicolumn{1}{c}{ Market Model } & \multicolumn{3}{c}{ Constant-Mean Model countries } \\
\hline & {$[-1,1]$} & {$[\mathbf{0 , 0}]$} & {$[\mathbf{0 , 1}]$} & {$[\mathbf{0 , 5}]$} & {$[-1, \mathbf{1}]$} & {$[\mathbf{0 , 0}]$} & {$[\mathbf{0 , 1}]$} & {$[\mathbf{0 , 5}]$} \\
\hline CAR (\%) & $\mathbf{- 1 . 1 6 0 2}$ & $\mathbf{- 0 . 0 9 6 7}$ & $\mathbf{- 1 . 0 2 3 0}$ & $\mathbf{0 . 5 2 0 8}$ & $\mathbf{2 . 2 8 3 2}$ & $\mathbf{0 . 9 7 3 8}$ & $\mathbf{0 . 1 1 4 9}$ & $\mathbf{- 2 . 4 6 7 6}$ \\
$\theta_{1}$ & $(-0.785)$ & $(-0.196)$ & $(-1.039)$ & $(0.176)$ & $(0.996)$ & $(1.274)$ & $(0.075)$ & $(-0.538)$ \\
$\theta_{2}$ & $(-0.570)$ & $(-0.143)$ & $(-0.754)$ & $(0.128)$ & $(0.978)$ & $(1.251)$ & $0.074)$ & $(-0.529)$ \\
$\#$ Positive AR & 2 & 3 & 2 & 3 & 4 & 4 & 2 & 3 \\
$\tau_{1}$ & $(-0.447)$ & $(0.447)$ & $(-0.447)$ & $(0.447$ & $(1.342$ & $(1.342)$ & $(-0.447$ & $(0.447)$ \\
\hline
\end{tabular}

PANEL B. Winter Olympic Games

\begin{tabular}{ccccccccc}
\hline \multicolumn{1}{c}{ Market Model } & \multicolumn{1}{c}{ Constant-Mean Model } \\
\hline & {$[-\mathbf{1 , 1}]$} & {$[\mathbf{0 , 0}]$} & {$[\mathbf{0 , 1}]$} & {$[\mathbf{0 , 5}]$} & {$[\mathbf{- 1 , 1 ]}$} & {$[\mathbf{0 , 0}]$} & {$[\mathbf{0 , 1}]$} & {$[\mathbf{0 , 5}]$} \\
\hline CAR (\%) & $\mathbf{0 . 5 0 7 4}$ & $\mathbf{0 . 2 8 0 2}$ & $\mathbf{- 0 . 0 1 6 0}$ & $\mathbf{0 . 5 2 5 3}$ & $\mathbf{0 . 8 8 7 0}$ & $\mathbf{0 . 6 3 6 7}$ & $\mathbf{0 . 2 6 1 9}$ & $\mathbf{0 . 7 7 1 7}$ \\
$\theta_{1}$ & $(0.313)$ & $(0.518)$ & $(-0.015)$ & $(0.162)$ & $(0.514)$ & $(1.106)$ & $(0.227)$ & $(0.223)$ \\
$\theta_{2}$ & $(0.321)$ & $(0.532)$ & $(-0.015)$ & $(0.166)$ & $(0.518)$ & $(1.116)$ & $(0.229)$ & $(0.225)$ \\
$\#$ Positive AR & 2 & 3 & 3 & 1 & 2 & 4 & 4 & 2 \\
$\tau_{1}$ & $(-0.447)$ & $(0.447)$ & $(0.447)$ & $(-1.342)$ & $(-0.447)$ & $(1.342)$ & $(1.342)$ & $(-0.447)$ \\
\hline
\end{tabular}


Table 6 (ctd.)

Abnormal returns at and around the announcement date: losing countries

PANEL C. World Exhibitions

\begin{tabular}{ccccccccc}
\hline \multicolumn{1}{c}{ Market Model } & \multicolumn{7}{c}{ Constant-Mean Model contries } \\
\hline & {$[-1,1]$} & {$[\mathbf{0 , 0}]$} & {$[\mathbf{0 , 1}]$} & {$[\mathbf{0 , 5}]$} & {$[-1,1]$} & {$[\mathbf{0 , 0}]$} & {$[\mathbf{0 , 1}]$} & {$[\mathbf{0 , 5}]$} \\
\hline CAR (\%) & $\mathbf{0 . 4 7 2 7}$ & $\mathbf{0 . 1 8 9 8}$ & $\mathbf{0 . 3 3 4 3}$ & $\mathbf{0 . 9 2 3 7}$ & $\mathbf{0 . 0 7 9 8}$ & $\mathbf{0 . 5 2 3 0}$ & $\mathbf{0 . 0 5 1 7}$ & $\mathbf{0 . 3 3 4 7}$ \\
$\boldsymbol{\theta}_{1}$ & $(0.803)$ & $(0.968)$ & $(0.852)$ & $(0.785)$ & $(0.046)$ & $(0.896)$ & $(0.044)$ & $(0.096)$ \\
$\boldsymbol{\theta}_{2}$ & $(0.791)$ & $(0.953)$ & $(0.839)$ & $(0.773)$ & $(0.044)$ & $(0.866)$ & $(0.043)$ & $(0.092)$ \\
\# Positive AR & 3 & 3 & 3 & 4 & 2 & 4 & 2 & 3 \\
$\tau_{1}$ & $(1.000)$ & $(1.000)$ & $(1.000)$ & $(2.000)^{b}$ & $(0.000)$ & $(2.000)^{b}$ & $(0.000)$ & $(1.000)$ \\
\hline
\end{tabular}

PANEL D. World Football Cups (South Africa)

\begin{tabular}{ccccccccc}
\hline & \multicolumn{3}{c}{ Market Model } & \multicolumn{5}{c}{ Constant-Mean Model } \\
\hline & {$[-1,1]$} & {$[0,0]$} & {$[0,1]$} & {$[0,5]$} & {$[-1,1]$} & {$[0,0]$} & {$[0,1]$} & {$[0,5]$} \\
\hline CAR (\%) & 0.9040 & 0.4095 & 0.6283 & 0.5535 & 0.1536 & -0.073 & -0.493 & 1.4042 \\
\hline
\end{tabular}




\section{Table 7 \\ Cross-sectional regressions}

This table reports GLS regressions estimates with host country industry cumulative abnormal returns $C A R[0,1]$ as the dependent variable. Abnormal returns are constant-mean adjusted. SIZE is the ratio between the event capital expenditure and the host country GDP; $L A G$ is the time lag between the announcement and the moment of the event; LIQ is the ratio between of the country market capitalization and GDP; REC is a dummy that equals 1 if the economy is in recession at the time of the event and 0 otherwise; EXP is a dummy that equals 1 if the economy is in expansion at the time of the event and 0 otherwise; REP is the weight of the industry market capitalization in aggregate market capitalization; VOT is the difference in the percentage of votes between the winning and the losing country with the largest number of votes in the last round. D_SOG. D_WOG. D_WFC. D_WE and D_EE are the dummies for the type of event (Summer Olympic Games, Winter Olympic Games, World Exhibitions and World Specialized Exhibitions). The last two rows report, respectively, the number of observations and the adjusted $\mathrm{R}^{2}$. Industry fixed effects coefficients are not reported. $t$-statistics are shown in parentheses. ${ }^{a},{ }^{b}$ and ${ }^{c}$ denote statistical significance at the $1 \%, 5 \%$ and $10 \%$ levels for bilateral tests.

\begin{tabular}{|c|c|c|}
\hline Independent variables & \multicolumn{2}{|c|}{$\begin{array}{l}\text { Coefficients of industry fixed effects } \\
\text { regression models }\end{array}$} \\
\hline & (1) & (2) \\
\hline SIZE & -0.0008 & 0.0230 \\
\hline & $(-0.016)$ & $(0.475)$ \\
\hline \multirow{2}{*}{$L A G$} & $-0.0001^{a}$ & $-0.0001^{a}$ \\
\hline & $(-2.833)$ & $(-2.795)$ \\
\hline \multirow{2}{*}{ LIQ } & -0.0058 & -0.0052 \\
\hline & $(0.209)$ & $(-0,190)$ \\
\hline \multirow[t]{2}{*}{ REC } & 0.0033 & 0.0035 \\
\hline & $(0.944)$ & (1.003) \\
\hline & -0.0024 & -0.0022 \\
\hline EXP & $(-1.339)$ & $(-1.266)$ \\
\hline \multirow[t]{2}{*}{ REP } & $0.0373^{b}$ & \\
\hline & $(2.082)$ & \\
\hline \multirow[t]{2}{*}{$V O T$} & $-0.02320^{a}$ & $-0.0235^{a}$ \\
\hline & $(-7.956)$ & $(-8.108)$ \\
\hline D_SOG & -0.0006 & -0.0009 \\
\hline & $(-0.132)$ & $(-0.198)$ \\
\hline \multirow[t]{2}{*}{$D \_W O G$} & $-0.0134^{a}$ & $-0.0135^{a}$ \\
\hline & $(-3.138)$ & $(-3.161)$ \\
\hline$D \_W F C$ & 0.0069 & 0.0068 \\
\hline & $(1.465)$ & $(1.440)$ \\
\hline$D \_W E$ & $0.0109^{b}$ & $0.0115^{b}$ \\
\hline & $(2.124)$ & $(2.228)$ \\
\hline \# obs./ \# events & $699 / 32$ & $701 / 32$ \\
\hline Adj. R2 & $19.1 \%$ & $18.8 \%$ \\
\hline
\end{tabular}




\section{Table 8}

\section{Partial Anticipation Model I - Estimated Parameters}

This table reports OLS regressions of cumulative abnormal returns over the event day and next-day $C A R[0,1]$ for winning and losing countries. Abnormal returns are constant-mean adjusted. $p$ is defined as the probability of country hosting the event and is given by the percentage of votes received by the country in the last round of voting; $D$ is a dummy variable that equals 1 if the country is nominated and 0 otherwise. The table also reports the number of observations and the adjusted $\mathrm{R}^{2}$. The last row shows the $p$-values for linear tests of significance for the parameters. Estimates are multiplied by $100 .{ }^{a},{ }^{b}$ and ${ }^{c}$ denote statistical significance at the $1 \%, 5 \%$ and $10 \%$ levels for bilateral tests.

$$
C A R_{i}=\alpha+\phi p_{i}+\delta D_{i}+\mu_{i}
$$

PANEL A. Unbalanced panel

\begin{tabular}{|c|c|c|}
\hline & Estimate & $t$-value \\
\hline Intercept & 0.8598 & $(0.768)$ \\
\hline$p$ & -3.8013 & $(-1.608)$ \\
\hline$D$ & 1.5138 & $(1.810)^{\mathrm{c}}$ \\
\hline \# (winning/losing) & \multicolumn{2}{|c|}{$39(24 / 15)$} \\
\hline Adj. R2 & \multicolumn{2}{|c|}{$4.1 \%$} \\
\hline Null Hypothesis & \multicolumn{2}{|c|}{$p$-value (Wald test) } \\
\hline$|\alpha|=|\delta|$ & \multicolumn{2}{|c|}{$(0.580)$} \\
\hline
\end{tabular}

PANEL B. Balanced panel

\begin{tabular}{ccc}
\hline & Estimate & t-value \\
Intercept & -0.9437 & $(-0.249)$ \\
$p$ & 0.4791 & $(0.055)$ \\
$D$ & 1.0229 & $(0.684)$ \\
\hline A (winning/losing) & \multicolumn{2}{c}{$\# 28(14 / 14)$} \\
\hline Adj. R2 & \multicolumn{2}{c}{$0.0 \%$} \\
\hline Null Hypothesis & \multicolumn{2}{c}{$p$-value (Wald test) } \\
\hline$|\alpha|=|\delta|$ & $(0.987)$ \\
\hline
\end{tabular}




\section{Table 9}

\section{Partial Anticipation Model II - Estimated Parameters}

This table reports OLS regressions of cumulative abnormal returns over the event day and next-day $C A R[0.1]$ for winning and losing countries. Abnormal returns are constant-mean adjusted. PS is a dummy variable that equals 1 when the announcement news are a partial surprise and 0 otherwise; $T S$ is a dummy variable that equals 1 when the announcement news are an almost total surprise and $O$ otherwise; and $D$ is a dummy variable that equals 1 if the country is nominated and 0 otherwise. The table also reports the number of observations and the adjusted $\mathrm{R}^{2}$. The last rows show the $p-$ values for several tests of significance for the sum of parameters. Estimates are multiplied by 100 . $a, b$ and ${ }^{c}$ denote statistical significance at the $1 \%, 5 \%$ and $10 \%$ levels for bilateral tests.

$$
C A R_{i}=\varphi_{0}+\varphi_{1} P S_{i}+\varphi_{2} T S_{i}+\lambda_{0} D_{i}+\lambda_{1} D_{i} P S_{i}+\lambda_{2} D_{i} T S_{i}+\omega_{i}
$$

PANEL A. Unbalanced panel

\begin{tabular}{|c|c|c|}
\hline & Estimate & $t$-value \\
\hline Intercept & 0.5374 & $(0.636)$ \\
\hline PS & -0.8564 & $(-0.877)$ \\
\hline$T S$ & -3.8508 & $(-3.220)^{a}$ \\
\hline$D$ & -1.2201 & $(-1.324)$ \\
\hline$D * P S$ & 1.0137 & $(0.823)$ \\
\hline$D^{*} T S$ & 8.2827 & $(5.487)^{a}$ \\
\hline \# (winning/losing) & \multicolumn{2}{|c|}{$39(24 / 15)$} \\
\hline Adj. R2 & \multicolumn{2}{|c|}{$46.3 \%$} \\
\hline Null Hypothesis & \multicolumn{2}{|c|}{$p$-value (Wald test) } \\
\hline Intercept $+P S=0$ & \multicolumn{2}{|r|}{$(0.513)$} \\
\hline Intercept $+T S=0$ & \multicolumn{2}{|r|}{$(0.000)^{a}$} \\
\hline Intercept $+P S=$ Intercept $+T S$ & \multicolumn{2}{|r|}{$(0.002)^{a}$} \\
\hline Intercept $+D=0$ & \multicolumn{2}{|c|}{$(0.062)^{c}$} \\
\hline Intercept $+P S+D+D * P S=0$ & \multicolumn{2}{|r|}{$(0.422)$} \\
\hline Intercept $+T S+D+D * T S=0$ & \multicolumn{2}{|c|}{$(0.000)^{a}$} \\
\hline Intercept $+P S+D+D * P S=\operatorname{Intercept} t+T S+D+D * T S$ & \multicolumn{2}{|c|}{$(0.000)^{a}$} \\
\hline $\mid$ Intercept $|=|$ Intercept $+D \mid$ & \multicolumn{2}{|r|}{$(0.185)$} \\
\hline
\end{tabular}


Table 9 (ctd.)

Partial Anticipation Model II - Estimated Parameters

PANEL B. Balanced panel

\begin{tabular}{|c|c|c|}
\hline & Estimate & $t$-value \\
\hline Intercept & 0.5375 & $(0.685)$ \\
\hline PS & -0.7889 & $(-0.857)$ \\
\hline TS & -3.8508 & $(-3.468)^{a}$ \\
\hline$D$ & -1.1494 & $(-1.248)$ \\
\hline$D * P S$ & 1.4165 & $(1.141)$ \\
\hline$D^{*} T S$ & 9.3502 & $(6.050)^{a}$ \\
\hline \# (winning/losing) & \multicolumn{2}{|c|}{$28(14 / 14)$} \\
\hline Adj. R2 & \multicolumn{2}{|c|}{$60.0 \%$} \\
\hline Null Hypothesis & \multicolumn{2}{|c|}{$p$-value (Wald test) } \\
\hline Intercept $+P S=0$ & \multicolumn{2}{|c|}{$(0.601)$} \\
\hline Intercept $+T S=0$ & \multicolumn{2}{|c|}{$(0.000)^{a}$} \\
\hline Intercept $+P S=$ Intercept $+T S$ & \multicolumn{2}{|c|}{$(0.001)^{a}$} \\
\hline Intercept $+D=0$ & \multicolumn{2}{|c|}{$(0.203)$} \\
\hline Intercept $+P S+D+D * P S=0$ & \multicolumn{2}{|c|}{$(0.982)$} \\
\hline Intercept $+T S+D+D^{*} T S=0$ & \multicolumn{2}{|c|}{$(0.000)^{a}$} \\
\hline Intercept $+P S+D+D * P S=$ Intercept $+T S+D+D * T S$ & \multicolumn{2}{|c|}{$(0.000)^{a}$} \\
\hline $\mid$ Intercept $|=|$ Intercept $+D \mid$ & \multicolumn{2}{|c|}{$(0.212)$} \\
\hline
\end{tabular}




\section{Additional Tables}

Table A1

Announcement Dates

The table below shows the announcement dates for the mega-events analysed.

PANEL A. Summer Olympic Games

\begin{tabular}{|c|c|c|}
\hline Event Year & Hosting Country & Announcement Date \\
\hline 1960 & Italy (Rome) & 16-May-1955 \\
\hline 1964 & Japan (Tokyo) & 26-May-1959 \\
\hline 1968 & México (Mexico City) & 18-Oct-1963 \\
\hline 1972 & Germany (Munich) & 26-Apr-1966 \\
\hline 1976 & Canada (Montreal) & 13-May-1970 \\
\hline 1980 & Soviet Union (Moscow) & 23-Oct-1974 \\
\hline 1984 & USA (Los Angeles) & 18-May -1978 \\
\hline 1988 & South Korea (Seoul) & 30-Sep-1981 \\
\hline 1992 & Spain (Barcelona) & $17-$ Oct-1986 \\
\hline 1996 & USA (Atlanta) & 18-Sept1990 \\
\hline 2000 & Australia (Sydney) & 23-Sep-1993 \\
\hline 2004 & Greece (Athens) & 05-Sep-1997 \\
\hline 2008 & China (Beijing) & 13-July-2001 \\
\hline
\end{tabular}

Source: International Olympic Committee

PANEL B. Winter Olympic Games

\begin{tabular}{|c|c|c|}
\hline Event Year & Hosting Country & Announcement Date \\
\hline 1960 & USA (Squaw Valley) & 14-June-1955 \\
\hline 1964 & Austria (Innsbruck) & 25-May -1959 \\
\hline 1968 & France (Grenoble) & 28-May-1964 \\
\hline 1972 & Japan (Sapporo) & 26-Apr-1966 \\
\hline 1976 & Austria (Innsbruck) & 04-Feb-1973 \\
\hline 1980 & EUA (Lake Placid) & 23-Oct-1974 \\
\hline 1984 & Yugoslavia (Sarajevo) & 18-May-1978 \\
\hline 1988 & Canada (Calgary) & 30-Sep-1981 \\
\hline 1992 & France (Albertville) & 17-Oct-1986 \\
\hline 1994 & Norway (Lillehammer) & 15-Sep-1988 \\
\hline 1998 & Japan (Nagano) & 15-Jun-1991 \\
\hline 2002 & EUA (Salt Lake City) & 16-Jun-1995 \\
\hline 2006 & Italy (Turin) & 19-Jun-1999 \\
\hline 2010 & Canada (Vancouver) & 02-Jul-2003 \\
\hline
\end{tabular}

Source: International Olympic Committee 
Table A1 (ctd.)

Announcement Dates

PANel C. World Football Cups

\begin{tabular}{|c|c|c|}
\hline Event Year & Hosting Country & Announcement Date \\
\hline 1970 & México & 08-Oct-1964 \\
\hline 1974 & Germany & 08-Jul-1966 \\
\hline 1978 & Argentina & 08-Jul-1966 \\
\hline 1982 & Spain & 08-Jul-1966 \\
\hline 1986 & Mexico & 20-Мay -1983 \\
\hline 1990 & Italy & 19-May-1984 \\
\hline 1994 & USA & 4-Jul-1988 \\
\hline 1998 & France & 2-Jul-1992 \\
\hline 2002 & Japan/South Korea & 31-May -1996 \\
\hline 2006 & Germany & 06-Jul-2000 \\
\hline
\end{tabular}

Source: FIFA.

PANEL D. European Football Cups

\begin{tabular}{|c|c|c|}
\hline Event Year & Hosting Country & Announcement Date \\
\hline 1976 & Yugoslavia & $27-J a n-1976$ \\
\hline 1980 & Italy & $12-$ Nov-1977 \\
\hline 1984 & France & $14-$ Mar-1985 \\
\hline 1988 & Germany & $16-$ Dec-1988 \\
\hline 1992 & Sweden & $05-$ May-1992 \\
\hline 1996 & England & $31-$ Mar -1995 \\
\hline 2000 & Belgium / Netherlands & $12-$ Oct-1999 \\
\hline 2004 & Portugal & $12-$ Dec-2002 \\
\hline 2008 & Austria / Switzerland & \\
\hline
\end{tabular}

Source: UEFA. 
Table A1 (ctd.)

\section{Announcement Dates}

PANEL E. World and Specialized Exhibitions

\begin{tabular}{|c|c|c|c|}
\hline Event Year & $\begin{array}{c}\text { Universal/World } \\
\text { /Specialized }\end{array}$ & Host Country & $\begin{array}{c}\text { Announcement } \\
\text { Date }\end{array}$ \\
\hline 1970 & $\mathrm{U}$ & Japan (Osaka) & 14-Set-1965 \\
\hline 1972 & $\mathrm{~S}$ & Netherlands (Amsterdam) & 21-Mar-1968 \\
\hline 1973 & $\mathrm{~S}$ & Germany (Hamburg) & 06-May-1969 \\
\hline 1974 & $\mathrm{~S}$ & Austria (Vienna) & 16-Jun-1969 \\
\hline 1974 & $\mathrm{U}$ & USA (Spokane) & 16-Feb-1971 \\
\hline 1975 & $\mathrm{U}$ & Japan (Okinawa) & 24-Mar-1972 \\
\hline 1980 & S & Canada (Montreal) & 14-Feb-1979 \\
\hline 1981 & $S$ & Bulgaria (Plovdiv) & 06-Jun1980 \\
\hline 1982 & $S$ & Netherlands (Amsterdam) & 16-Feb-1979 \\
\hline 1982 & $\mathrm{U}$ & USA (Knoxville) & 15-Abr-1977 \\
\hline 1983 & $\mathrm{~S}$ & Germany (Munich) & 21-Aug-1979 \\
\hline 1984 & $\mathrm{~S}$ & England (Liverpool) & 09-Feb-1982 \\
\hline 1984 & $\mathrm{~W}$ & USA (New Orleans) & 12-Jun-1980 \\
\hline 1985 & $\mathrm{~W}$ & Japan (Tsukuba) & 26-Nov-1980 \\
\hline 1985 & W & Bulgaria (Plovdiv) & 30-May-1984 \\
\hline 1986 & W & Canada (Vancouver) & $12-$ Oct-1980 \\
\hline 1988 & $\mathrm{~W}$ & Australia (Brisbane) & 15-Jun-1983 \\
\hline 1990 & $\mathrm{~S}$ & Japan (Osaka) & 26-May-1986 \\
\hline 1992 & W & Spain (Seville) & 8-Dec-1982 \\
\hline 1992 & $\mathrm{~S}$ & Italy (Genoa) & 18-Jun-1982 \\
\hline 1992 & $\mathrm{~S}$ & New Zeland (Haye-Z.) & 25-Nov-1986 \\
\hline 1993 & S & Germany (Stuttgart) & 25-May-1989 \\
\hline 1993 & $\mathrm{~W}$ & South Korea (Taejon) & 14-Jun-1990 \\
\hline 1998 & $\mathrm{~W}$ & Portugal (Lisbon) & 23-Jun-1992 \\
\hline 1999 & $S$ & China (Kunming) & 4-Dec-1994 \\
\hline 2000 & $\mathrm{~W}$ & Germany (Hanover) & 14-Jun-1990 \\
\hline 2002 & $\mathrm{~S}$ & Netherlands (Haarlemmer) & 15-Jun-1995 \\
\hline 2003 & $\mathrm{~S}$ & Germany (Rostock) & 13-Dec-1995 \\
\hline 2005 & W & Japan (Aichi) & 12-Jun-1997 \\
\hline 2010 & $\mathrm{~W}$ & China (Shanghai) & 03-Dec-2002 \\
\hline
\end{tabular}

Source: Bureau International de Expositions (BIE). 
Table A1 (ctd.)

\section{Announcement Dates}

PANEL G. European Capitals of Culture

\begin{tabular}{|c|c|c|}
\hline Event Year & Hosting Country & Announcement Date \\
\hline 1985 & Greece (Athens) & 22-Nov-1984 \\
\hline 1986 & Italy (Florence) & \multirow{4}{*}{ 28-May-1985 } \\
\hline 1987 & Netherlands (Amsterdam) & \\
\hline 1988 & Germany (Berlin) & \\
\hline 1989 & France (Paris) & \\
\hline 1990 & Scotland (Glasgow) & 13-Nov-1986 \\
\hline 1992 & Spain (Madrid) & \multirow{2}{*}{ 27-May-1988 } \\
\hline 1993 & France (Anvers) & \\
\hline 1991 & Ireland (Dublin) & \multirow{4}{*}{ 18-May-1989 } \\
\hline 1994 & Portugal (Lisbon) & \\
\hline 1995 & Luxemburg (Luxemburg) & \\
\hline 1996 & Denmark (Copenhagen) & \\
\hline 1997 & Greece (Thessaloniki) & 18-May-1992 \\
\hline 1998 & Sweden (Stockholm) & \multirow{2}{*}{ 05-Nov-1993 } \\
\hline 1999 & Germany (Weimar) & \\
\hline 2000 & $\begin{array}{c}\text { France (Avignon); Norway (Bergen); Italy } \\
\text { (Bologna); Belgium (Brussels); Poland } \\
\text { (Kracovia); Czech Rep. (Prague); Finland } \\
\text { (Helsinki); Spain (Santiago } \\
\text { Compostela);Island (Reykjavik) }\end{array}$ & 20-Nov-1995 \\
\hline 2001 & Netherlands (Rotterdam); Portugal (Porto) & \multirow{4}{*}{ 28-May-1998 } \\
\hline 2002 & Belgium (Bruges); Spain (Salamanca) & \\
\hline 2003 & Austria (Graz) & \\
\hline 2004 & France (Lille); Italy (Genoa) & \\
\hline 2005 & Ireland (Cork) & 7-May-2002 \\
\hline 2006 & Greece (Patras) & 6-May-2003 \\
\hline 2008 & England (Liverpool) & 4-Jun-2003 \\
\hline
\end{tabular}

Source: EC. 
Table A2

Individual Market Abnormal Returns

This table reports, for each market, the abnormal returns (AR) at the announcement date and cumulative abnormal returns (CAR) for several other event windows after the announcement day. Abnormal returns are constant-mean and risk-adjusted returns. Model parameters were estimated regressing market index returns on the world market index over the period [-120, -20] in event time $t$-statistics are shown in parentheses. ${ }^{a},{ }^{b}$ and ${ }^{c}$ denote statistical significance at the $1 \%, 5 \%$ and $10 \%$ levels for bilateral tests.

PANEL A. Summer Olympic Games

\begin{tabular}{|c|c|c|c|c|c|c|}
\hline & \multicolumn{3}{|c|}{ Market Model } & \multicolumn{3}{|c|}{ Constant-Mean Model } \\
\hline & {$[0,0]$} & {$[0,1]$} & {$[0,5]$} & {$[0,0]$} & {$[0,1]$} & {$[0,5]$} \\
\hline $\begin{array}{l}\text { USA } \\
1984\end{array}$ & $\begin{array}{l}-0.463 \\
(0.247)\end{array}$ & $\begin{array}{l}-0.415 \\
(0.604)\end{array}$ & $\begin{array}{l}-1.358 \\
(0.571)\end{array}$ & $\begin{array}{l}-1.000 \\
(0.128)\end{array}$ & $\begin{array}{l}-1.559 \\
(0.236)\end{array}$ & $\begin{array}{l}-2.977 \\
(0.450)\end{array}$ \\
\hline $\begin{array}{c}\text { SPAIN } \\
1992\end{array}$ & $\begin{array}{l}-0.258 \\
(0.840)\end{array}$ & $\begin{array}{l}-2.019 \\
(0.431)\end{array}$ & $\begin{array}{l}-4.613 \\
(0.549)\end{array}$ & $\begin{array}{l}-0.066 \\
(0.961)\end{array}$ & $\begin{array}{l}-1.699 \\
(0.533)\end{array}$ & $\begin{array}{l}-4.856 \\
(0.552)\end{array}$ \\
\hline $\begin{array}{l}\text { USA } \\
1996\end{array}$ & $\begin{array}{c}0.790 \\
(0.230)\end{array}$ & $\begin{array}{c}0.767 \\
(0.559)\end{array}$ & $\begin{array}{c}0.207 \\
(0.958)\end{array}$ & $\begin{array}{c}0.242 \\
(0.768)\end{array}$ & $\begin{array}{l}-0.351 \\
(0.830)\end{array}$ & $\begin{array}{l}-2.777 \\
(0.572)\end{array}$ \\
\hline $\begin{array}{l}\text { AUSTRALIA } \\
2000\end{array}$ & $\begin{array}{c}0.448 \\
(0.488)\end{array}$ & $\begin{array}{c}1.502 \\
(0.247)\end{array}$ & $\begin{array}{c}1.730 \\
(0.656)\end{array}$ & $\begin{array}{c}0.440 \\
(0.498)\end{array}$ & $\begin{array}{c}1.473 \\
(0.257)\end{array}$ & $\begin{array}{c}1.660 \\
(0.670)\end{array}$ \\
\hline $\begin{array}{l}\text { GREECE } \\
2004\end{array}$ & $\begin{array}{c}0.114 \\
(0.944)\end{array}$ & $\begin{array}{c}7.758 \\
(0.019)^{b}\end{array}$ & $\begin{array}{c}6.367 \\
(0.519)\end{array}$ & $\begin{array}{c}0.216 \\
(0.896)\end{array}$ & $\begin{array}{c}7.856 \\
(0.019)^{b}\end{array}$ & $\begin{array}{r}5.765 \\
(0.563)\end{array}$ \\
\hline $\begin{array}{c}\text { CHINA } \\
2008\end{array}$ & $\begin{array}{l}-1.111 \\
(0.515)\end{array}$ & $\begin{array}{l}-2.819 \\
(0.409)\end{array}$ & $\begin{array}{l}-9.053 \\
(0.378)\end{array}$ & $\begin{array}{l}-1.049 \\
(0.543)\end{array}$ & $\begin{array}{l}-2.194 \\
(0.399)\end{array}$ & $\begin{array}{l}-9.069 \\
(0.381)\end{array}$ \\
\hline
\end{tabular}


Table A2

Individual Market Abnormal Returns (ctd.)

PANel B. Winter Olympic Games

\begin{tabular}{|c|c|c|c|c|c|c|}
\hline & \multicolumn{3}{|c|}{ Market Model } & \multicolumn{3}{|c|}{$\begin{array}{l}\text { Constant-Mean } \\
\text { Model }\end{array}$} \\
\hline & {$[0,0]$} & {$[0,1]$} & {$[0,5]$} & {$[0,0]$} & {$[0,1]$} & {$[0,5]$} \\
\hline USA & -0.242 & 0.068 & 0.333 & -2.595 & -3.353 & 3.810 \\
\hline 1980 & $(0.432)$ & $(0.912)$ & $(0.857)$ & $(0.06)^{c}$ & $(0.226)$ & $(0.645)$ \\
\hline CANADA & -0.800 & 0.078 & 0.060 & -0.704 & 0.238 & 2.344 \\
\hline 1988 & $(0.147)$ & $(0.943)$ & $(0.985)$ & $(0.270)$ & $(0.852)$ & $(0.542)$ \\
\hline FRANCE & -1.005 & -1.840 & 3.752 & -1.260 & -2.598 & -1.753 \\
\hline 1992 & $(0.473)$ & $(0.511)$ & $(0.655)$ & $(0.379)$ & $(0.364)$ & (0.838) \\
\hline NORWAY & 0.124 & 1.812 & 3.307 & 0.250 & 1.919 & 3.034 \\
\hline 1994 & $(0.919)$ & $(0.456)$ & $(0.650)$ & $(0.839)$ & $(0.437)$ & $(0.682)$ \\
\hline JAPAN & -0.238 & -0.284 & -1.878 & 0.296 & -0.309 & -2.907 \\
\hline 1998 & $(0.772)$ & $(0.862)$ & $(0.703)$ & $(0.801)$ & $(0.895)$ & $(0.680)$ \\
\hline USA & 0.388 & -0.464 & -1.251 & 0.408 & -0.548 & -1.379 \\
\hline 2002 & $(0.385)$ & $(0.604)$ & $(0.641)$ & $(0.372)$ & $(0.549)$ & $(0.615)$ \\
\hline ITALY & 0.347 & -0.669 & -3.543 & -0.133 & -2.023 & -7.596 \\
\hline 2006 & $(0.719)$ & $(0.728)$ & $(0.539)$ & $(0.915)$ & $(0.414)$ & $(0.307)$ \\
\hline CANADA & -0.723 & -0.553 & 0.332 & -0.093 & 0.033 & 1.272 \\
\hline 2008 & $(0.060)^{c}$ & $(0.473)$ & $(0.886)$ & $(0.877)$ & $(0.978)$ & $(0.725)$ \\
\hline
\end{tabular}


Table A2 (ctd.)

Individual Market Abnormal Returns

PANEL C. World Football Cups

6 countries

\begin{tabular}{ccccccc}
\hline & \multicolumn{5}{c}{ Market Model } & \multicolumn{3}{c}{ Constant-Mean Model } \\
& {$[\mathbf{0 , 0}]$} & {$[\mathbf{0 , 1}]$} & {$[\mathbf{0 , 5}]$} & {$[\mathbf{0 , 0}]$} & {$[\mathbf{0 , 1}]$} & {$[\mathbf{0 , 5}]$} \\
\hline ITALY & -1.385 & -1.781 & -1.603 & -1.681 & -2.129 & -2.381 \\
$\mathbf{1 9 9 0}$ & $(0.170)$ & $(0.377)$ & $(0.791)$ & $(0.098)$ & $(0.294)$ & $(0.695)$ \\
USA & 1.004 & 0.868 & -1.396 & -0.062 & 1.247 & -0.737 \\
$\mathbf{1 9 9 4}$ & $(0.331)$ & $(0.674)$ & $(0.822)$ & $(0.960)$ & $(0.614)$ & $(0.921)$ \\
FRANCE & -0.547 & -0.144 & -1.842 & -0.313 & 0.128 & -1.807 \\
$\mathbf{1 9 9 8}$ & $(0.496)$ & $(0.929)$ & $(0.702)$ & $(0.710)$ & $(0.939)$ & $(0.721)$ \\
JAPAN & 0.325 & -0.556 & -0.744 & 0.383 & -0.836 & -1.251 \\
$\mathbf{2 0 0 0}$ & $(0.627)$ & $(0.677)$ & $(0.853)$ & $(0.590)$ & $(0.557)$ & $(0.770)$ \\
SOUTH KOREA & 0.691 & 0.522 & 0.716 & 0.745 & 0.237 & 0.189 \\
$\mathbf{2 0 0 4}$ & $(0.546)$ & $(0.820)$ & $(0.917)$ & $(0.525)$ & $(0.920)$ & $(0.979)$ \\
GERMANY & -0.237 & -0.125 & 0.030 & -0.053 & 0.929 & 1.604 \\
$\mathbf{2 0 0 8}$ & $(0.849)$ & $(0.960)$ & $(0.997)$ & $(0.973)$ & $(0.764)$ & $(0.863)$ \\
\hline
\end{tabular}


Table A2 (ctd.)

Individual Market Abnormal Returns

PANEL D. European Football Cups

\begin{tabular}{|c|c|c|c|c|c|c|}
\hline & \multicolumn{3}{|c|}{ Market Model } & \multicolumn{3}{|c|}{ Constant-Mean Model } \\
\hline & {$[0,0]$} & {$[0,1]$} & {$[0,5]$} & {$[0,0]$} & {$[0,1]$} & {$[0,5]$} \\
\hline ITALY & -0.338 & -0.443 & -1.062 & -0.323 & -0.420 & -1.008 \\
\hline 1980 & $(0.744)$ & $(0.831)$ & $(0.864)$ & $(0.755)$ & $(0.840)$ & $(0.871)$ \\
\hline FRANCE & -0.325 & -0.400 & -1.611 & -0.419 & -0.516 & -1.834 \\
\hline 1984 & $(0.814)$ & $(0.885)$ & $(0.846)$ & $(0.763)$ & $(0.853)$ & $(0.826)$ \\
\hline GERMANY & -0.801 & 0.276 & 0.818 & -1.081 & -0.313 & 0.143 \\
\hline 1988 & $(0.160)$ & $(0.808)$ & $(0.810)$ & $(0.071)^{c}$ & $(0.792)$ & $(0.968)$ \\
\hline SWEDEN & 1.490 & 1.445 & 2.175 & 1.575 & 1.371 & 1.818 \\
\hline 1992 & $(0.032)^{b}$ & $(0.295)$ & $(0.598)$ & $(0.030)^{b}$ & $(0.342)$ & $(0.674)$ \\
\hline $\begin{array}{l}\text { UNITED } \\
\text { KINGDOM }\end{array}$ & 0.290 & 1.161 & 1.953 & 0.305 & 1.543 & 2.977 \\
\hline 1996 & $(0.672)$ & $(0.397)$ & $(0.635)$ & $(0.674)$ & $(0.289)$ & $(0.495)$ \\
\hline BELGIUM & -0.790 & 0.210 & 2.089 & -0.419 & 0.199 & 2.730 \\
\hline 2000 & $(0.048)^{b}$ & $(0.791)$ & $(0.380)$ & $(0.321)$ & $(0.813)$ & $(0.280)$ \\
\hline NETHERLANDS & -1.894 & -1.366 & -0.659 & -1.294 & -1.368 & 0.408 \\
\hline 2000 & $(0.000)^{a}$ & $(0.154)$ & $(0.818)$ & $(0.016)^{b}$ & $(0.197)$ & $(0.898)$ \\
\hline PORTUGAL & 0.172 & 0.139 & -0.666 & 0.036 & -0.545 & -1.508 \\
\hline 2004 & $(0.832)$ & $(0.932)$ & $(0.891)$ & $(0.967)$ & $(0.752)$ & $(0.770)$ \\
\hline AUSTRIA & 0.155 & 0.488 & 1.014 & 0.140 & 0.315 & 0.837 \\
\hline 2008 & $(0.823)$ & $(0.725)$ & $(0.807)$ & $(0.855)$ & $(0.836)$ & $(0.855)$ \\
\hline SWITZERLAND & -0.217 & 0.298 & -0.084 & -0.314 & -0.621 & -1.091 \\
\hline 2008 & $(0.880)$ & $(0.917)$ & $(0.992)$ & $(0.885)$ & $(0.886)$ & $(0.933)$ \\
\hline
\end{tabular}


Table A2 (ctd.)

Individual Market Abnormal Returns

PANEL E. World Exhibitions

\begin{tabular}{|c|c|c|c|c|c|c|}
\hline & \multicolumn{3}{|c|}{ Market Model } & \multicolumn{3}{|c|}{ Constant-Mean Model } \\
\hline & {$[0,0]$} & {$[0,1]$} & {$[0,5]$} & {$[0,0]$} & {$[0,1]$} & {$[0,5]$} \\
\hline USA & -0.012 & 0.043 & -1.076 & 0.070 & -0.341 & -2.417 \\
\hline 1982 & $(0.959)$ & $(0.927)$ & $(0.443)$ & $(0.906)$ & $(0.775)$ & $(0.500)$ \\
\hline USA & -0.364 & -0.614 & -1.097 & -0.250 & 0.013 & -1.163 \\
\hline 1984 & $(0.514)$ & $(0.582)$ & $(0.743)$ & $(0.798)$ & $(0.995)$ & $(0.843)$ \\
\hline JAPAN & 0.156 & -0.098 & -0.558 & 0.147 & -0.127 & -0.810 \\
\hline 1985 & $(0.677)$ & $(0.896)$ & $(0.804)$ & $(0.698)$ & $(0.867)$ & $(0.721)$ \\
\hline CANADA & -1.069 & -0.485 & 1.389 & -0.151 & 0.422 & 2.084 \\
\hline 1986 & $(0.098)^{c}$ & $(0.706)$ & $(0.719)$ & $(0.861)$ & $(0.806)$ & $(0.686)$ \\
\hline AUSTRALIA & -1.038 & -2.826 & -2.560 & -0.988 & -2.614 & -2.179 \\
\hline 1988 & $(0.443)$ & $(0.297)$ & $(0.752)$ & $(0.467)$ & $(0.336)$ & $(0.789)$ \\
\hline SPAIN & -1.644 & -2.440 & -2.365 & -1.610 & -2.374 & -2.315 \\
\hline 1992 & $(0.040)^{b}$ & $(0.126)$ & $(0.619)$ & $(0.044)^{b}$ & $(0.136)$ & $(0.626)$ \\
\hline SOUTH KOREA & -1.311 & -0.856 & -3.371 & -1.245 & -0.861 & -3.634 \\
\hline 1993 & $(0.505)$ & $(0.828)$ & $(0.775)$ & $(0.530)$ & $(0.828)$ & $(0.760)$ \\
\hline PORTUGAL & -0.176 & -0.338 & -0.193 & -0.173 & -0.333 & -0.178 \\
\hline 1998 & $(0.696)$ & $(0.707)$ & $(0.943)$ & $(0.699)$ & $(0.711)$ & $(0.947)$ \\
\hline GERMANY & -0.238 & 0.040 & 2.882 & -0.116 & 0.107 & 2.761 \\
\hline 2000 & $(0.803)$ & $(0.983)$ & $(0.615)$ & $(0.909)$ & $(0.958)$ & $(0.650)$ \\
\hline JAPAN & 1.114 & 1.415 & 1.505 & 1.131 & 1.448 & 1.567 \\
\hline 2005 & $(0.314)$ & $(0.522)$ & $(0.820)$ & $(0.310)$ & $(0.515)$ & $(0.814)$ \\
\hline CHINA & 1.917 & 1.104 & 1.650 & 1.728 & 0.828 & 1.205 \\
\hline 2010 & $(0.076)^{c}$ & $(0.607)$ & $(0.798)$ & $(0.118)$ & $(0.706)$ & $(0.855)$ \\
\hline
\end{tabular}


Table A2 (ctd.)

Individual Market Abnormal Returns

PANEL F. Specialized Exhibitions

\begin{tabular}{|c|c|c|c|c|c|c|}
\hline & \multicolumn{3}{|c|}{ Market Model } & \multicolumn{3}{|c|}{ Constant-Mean Model } \\
\hline & {$[0,0]$} & {$[0,1]$} & {$[0,5]$} & {$[0,0]$} & {$[0,1]$} & {$[0,5]$} \\
\hline CANADA & 0.311 & 0.097 & 0.796 & 0.230 & -0.010 & 0.782 \\
\hline 1980 & $(0.618)$ & $(0.938)$ & $(0.831)$ & $(0.736)$ & $(0.994)$ & $(0.848)$ \\
\hline NETHERLANDS & 0.185 & 0.205 & 0.173 & 0.161 & 0.170 & 0.258 \\
\hline 1982 & $(0.812)$ & $(0.895)$ & $(0.970)$ & $(0.838)$ & $(0.914)$ & $(0.957)$ \\
\hline GERMANY & 0.232 & 0.137 & 0.447 & 0.191 & 0.087 & 0.428 \\
\hline 1983 & $(0.651)$ & $(0.893)$ & $(0.885)$ & $(0.713)$ & $(0.933)$ & $(0.891)$ \\
\hline $\begin{array}{l}\text { UNITED } \\
\text { KINGDOM }\end{array}$ & -0.135 & 0.788 & 0.287 & -0.950 & 0.507 & -1.339 \\
\hline 1984 & $(0.892)$ & $(0.692)$ & $(0.962)$ & $(0.444)$ & $(0.838)$ & $(0.857)$ \\
\hline JAPAN & -0.052 & 0.131 & 1.305 & 0.237 & 0.515 & 0.647 \\
\hline 1990 & $(0.932)$ & $(0.914)$ & $(0.721)$ & $(0.747)$ & $(0.727)$ & $(0.884)$ \\
\hline ITALY & 0.811 & 3.257 & 1.621 & 0.641 & 2.884 & 1.876 \\
\hline 1992 & $(0.461)$ & $(0.140)$ & $(0.806)$ & $(0.568)$ & $(0.201)$ & $(0.781)$ \\
\hline GERMANY & 0.371 & 0.779 & 3.595 & 0.363 & 0.660 & 2.869 \\
\hline 1993 & $(0.564)$ & $(0.545)$ & $(0.353)$ & $(0.577)$ & $(0.612)$ & $(0.463)$ \\
\hline CHINA & 0.840 & 0.904 & -5.034 & 1.332 & 1.317 & -6.256 \\
\hline 1999 & $(0.563)$ & $(0.756)$ & $(0.564)$ & $(0.372)$ & $(0.659)$ & $(0.485)$ \\
\hline NETHERLANDS & 0.299 & -0.124 & 0.010 & 0.299 & -0.116 & 0.060 \\
\hline 2002 & $(0.500)$ & $(0.889)$ & $(0.997)$ & $(0.500)$ & $(0.896)$ & $(0.982)$ \\
\hline GERMANY & -0.388 & -0.172 & -0.900 & -0.356 & -0.088 & -1.118 \\
\hline 2003 & $(0.544)$ & $(0.893)$ & $(0.814)$ & $(0.587)$ & $(0.946)$ & $(0.776)$ \\
\hline
\end{tabular}


Table A2 (ctd.)

Individual Market Abnormal Returns

PANEL G. European Capitals of Culture

\begin{tabular}{|c|c|c|c|c|c|c|}
\hline & \multicolumn{3}{|c|}{ Market Model } & \multicolumn{3}{|c|}{ Constant-Mean Model } \\
\hline & {$[0,0]$} & {$[0,1]$} & {$[0,5]$} & {$[0,0]$} & {$[0,1]$} & {$[0,5]$} \\
\hline ITALY & -0.526 & 0.058 & -3.763 & -0.583 & 0.057 & -3.535 \\
\hline 1986 & $(0.603)$ & $(0.977)$ & $(0.535)$ & $(0.568)$ & $(0.978)$ & $(0.564)$ \\
\hline NETHERLANDS & 0.922 & 0.101 & -0.356 & 0.904 & 0.104 & -0.270 \\
\hline 1987 & $(0.223)$ & $(0.946)$ & $(0.937)$ & $(0.233)$ & $(0.945)$ & $(0.952)$ \\
\hline GERMANY & -0.183 & 0.371 & 2.027 & -0.228 & 0.380 & 2.256 \\
\hline 1988 & $(0.754)$ & $(0.752)$ & $(0.564)$ & $(0.702)$ & $(0.751)$ & $(0.529)$ \\
\hline FRANCE & 0.658 & 1.254 & 0.860 & 0.657 & 1.257 & 0.884 \\
\hline 1989 & $(0.330)$ & $(0.354)$ & $(0.832)$ & $(0.332)$ & $(0.353)$ & $(0.827)$ \\
\hline $\begin{array}{l}\text { UNITED } \\
\text { KINGDOM }\end{array}$ & 0.275 & 0.277 & 0.812 & -0.737 & -0.818 & -2.708 \\
\hline 1990 & $(0.703)$ & $(0.847)$ & $(0.851)$ & $(0.353)$ & $(0.606)$ & $(0.569)$ \\
\hline IRELAND & 0.303 & -0.517 & -2.127 & 0.382 & -0.665 & -2.162 \\
\hline 1991 & $(0.710)$ & $(0.752)$ & $(0.664)$ & $(0.642)$ & $(0.686)$ & $(0.661)$ \\
\hline SPAIN & 1.133 & 1.627 & 7.684 & 0.383 & 0.384 & 6.660 \\
\hline 1992 & $(0.320)$ & $(0.475)$ & $(0.262)$ & $(0.749)$ & $(0.873)$ & $(0.355)$ \\
\hline FRANCE & 1.669 & 2.902 & 4.329 & 1.131 & 2.081 & 4.535 \\
\hline 1993 & $(0.241)$ & $(0.308)$ & $(0.612)$ & $(0.441)$ & $(0.479)$ & $(0.607)$ \\
\hline DENMARK & -0.151 & 0.899 & -1.266 & -0.533 & -0.167 & -4.060 \\
\hline 1996 & $(0.872)$ & $(0.632)$ & $(0.822)$ & $(0.571)$ & $(0.929)$ & $(0.472)$ \\
\hline GREECE & -1.142 & -0.964 & -4.383 & -1.190 & -1.034 & -4.436 \\
\hline 1997 & $(0.321)$ & $(0.675)$ & $(0.525)$ & $(0.302)$ & $(0.653)$ & $(0.520)$ \\
\hline SWEDEN & -2.340 & -2.866 & -4.328 & -2.531 & -3.087 & -4.363 \\
\hline 1998 & $(0.016)^{b}$ & $(0.138)$ & $(0.453)$ & $(0.011)^{b}$ & $(0.114)$ & $(0.455)$ \\
\hline GERMANY & -1.898 & -2.104 & -2.370 & -2.020 & -2.245 & -2.398 \\
\hline 1999 & $(0.004)^{a}$ & $(0.101)$ & $(0.537)$ & $(0.002)^{a}$ & $(0.084)^{c}$ & $(0.536)$ \\
\hline BELGIAN & 0.911 & 0.729 & 1.088 & 0.950 & 0.797 & 1.185 \\
\hline 2000 & $(0.019)^{b}$ & $(0.344)$ & $(0.637)$ & $(0.016)^{b}$ & $(0.306)$ & $(0.611)$ \\
\hline SPAIN & 0.816 & 1.064 & 4.168 & 0.905 & 1.220 & 4.422 \\
\hline 2000 & $(0.219)$ & $(0.423)$ & $(0.296)$ & $(0.180)$ & $(0.366)$ & $(0.275)$ \\
\hline FINLAND & 1.526 & 0.544 & 1.365 & 1.776 & 0.989 & 2.173 \\
\hline 2000 & $(0.302)$ & $(0.854)$ & $(0.877)$ & $(0.239)$ & $(0.742)$ & $(0.810)$ \\
\hline FRANCE & -0.400 & -0.929 & 0.022 & -0.326 & -0.801 & 0.216 \\
\hline 2000 & $(0.620)$ & $(0.564)$ & $(0.996)$ & $(0.689)$ & $(0.622)$ & $(0.965)$ \\
\hline
\end{tabular}


Table A2 (ctd.)

Individual Market Abnormal Returns

PANEL G. European Capitals of Culture (cont.)

\begin{tabular}{|c|c|c|c|c|c|c|}
\hline & \multicolumn{3}{|c|}{ Market Model } & \multicolumn{3}{|c|}{ Constant-Mean Model } \\
\hline & {$[0,0]$} & {$[0,1]$} & {$[0,5]$} & {$[0,0]$} & {$[0,1]$} & {$[0,5]$} \\
\hline ITALY & -0.123 & -0.360 & -0.727 & -0.045 & -0.223 & -0.506 \\
\hline 2000 & $(0.894)$ & $(0.845)$ & $(0.896)$ & $(0.962)$ & $(0.904)$ & $(0.928)$ \\
\hline NORWAY & 0.716 & 1.555 & 3.100 & 0.764 & 1.639 & 3.245 \\
\hline 2000 & $(0.271)$ & $(0.232)$ & $(0.427)$ & $(0.243)$ & $(0.210)$ & $(0.407)$ \\
\hline POLAND & -3.457 & -3.836 & -3.234 & -3.452 & -3.831 & -3.268 \\
\hline 2000 & $(0.461)$ & $(0.140)$ & $(0.806)$ & $(0.568)$ & $(0.201)$ & $(0.781)$ \\
\hline $\begin{array}{c}\text { CZECH } \\
\text { REPUBLIC }\end{array}$ & -1.594 & -1.880 & -4.208 & -1.433 & -1.557 & -3.058 \\
\hline 2000 & $(0.001)^{a}$ & $(0.057)^{c}$ & $(0.173)$ & $(0.004)^{a}$ & $(0.114)$ & $(0.300)$ \\
\hline NETHERLANDS & -0.946 & 0.082 & -1.056 & -0.898 & -0.181 & -1.779 \\
\hline 2001 & $(0.200)$ & $(0.956)$ & $(0.811)$ & $(0.440)$ & $(0.938)$ & $(0.799)$ \\
\hline PORTUGAL & 0.155 & -0.942 & -7.473 & 0.179 & -1.152 & -8.056 \\
\hline 2001 & $(0.883)$ & $(0.654)$ & $(0.237)$ & $(0.884)$ & $(0.641)$ & $(0.277)$ \\
\hline BELGIAN & 0.713 & 1.547 & 1.883 & 0.727 & 1.364 & 1.371 \\
\hline 2002 & $(0.263)$ & $(0.224)$ & $(0.621)$ & $(0.380)$ & $(0.410)$ & $(0.782)$ \\
\hline SPAIN & 0.154 & -0.278 & 0.665 & 0.169 & -0.542 & -1.406 \\
\hline 2002 & $(0.874)$ & $(0.886)$ & (0.909) & $(0.890)$ & $(0.823)$ & $(0.847)$ \\
\hline AUSTRIA & -0.034 & -0.204 & -1.050 & -0.014 & -0.341 & -1.429 \\
\hline 2003 & $(0.965)$ & $(0.895)$ & $(0.821)$ & $(0.988)$ & $(0.848)$ & $(0.790)$ \\
\hline FRANCE & -0.222 & 0.426 & 1.625 & -0.212 & 0.174 & 0.919 \\
\hline 2004 & $(0.762)$ & $(0.771)$ & $(0.712)$ & $(0.832)$ & $(0.931)$ & $(0.878)$ \\
\hline ITALY & -0.938 & -1.279 & -2.348 & -0.926 & -1.554 & -3.120 \\
\hline 2004 & $(0.476)$ & $(0.627)$ & $(0.766)$ & $(0.541)$ & $(0.608)$ & $(0.731)$ \\
\hline IRELAND & -0.603 & -0.814 & 0.664 & -1.032 & 0.039 & 1.596 \\
\hline 2005 & $(0.603)$ & $(0.725)$ & $(0.924)$ & $(0.408)$ & $(0.987)$ & (0.831) \\
\hline GREECE & 0.362 & 1.336 & -1.496 & 0.969 & 1.808 & -0.481 \\
\hline 2006 & $(0.500)$ & $(0.889)$ & (0.997) & $(0.500)$ & $(0.896)$ & $(0.982)$ \\
\hline $\begin{array}{l}\text { UNITED } \\
\text { KINGDOM }\end{array}$ & -0.842 & -2.002 & -1.853 & 0.296 & 0.001 & 1.208 \\
\hline 2008 & $(0.407)$ & $(0.324)$ & $(0.761)$ & $(0.844)$ & $(0.999)$ & $(0.894)$ \\
\hline
\end{tabular}


Table A3

Descriptive Statistics

This table shows descriptive statistics of the events. SIZE is the ratio between the event capital expenditure and the host country GDP; $L A G$ is the time lag between the announcement and the moment of the event (number of months); VOT is the difference in the percentage of votes between the winning and the losing country with the largest number of votes in the last round. \# denotes the number of events used to computed the cross-sectional statistics.

PANel A. All events (\#32)

\begin{tabular}{lccccc}
\hline & Mean & Median & Minimum & Maximum & SD \\
\hline SIZE & 0.0124 & 0.0017 & 0.0000 & 0.1056 & 0.0245 \\
$\boldsymbol{L A G}$ & 68.7 & 70.5 & 13 & 120 & 23.1 \\
$\boldsymbol{V O T} \boldsymbol{T}$ & $56.3 \%$ & $38.7 \%$ & $2.3 \%$ & $100.0 \%$ & $42.1 \%$ \\
\hline
\end{tabular}

PANEL B. Summer Olympic Games (\#6)

\begin{tabular}{lccccc}
\hline & Mean & Median & Minimum & Maximum & SD \\
\hline SIZE & 0.0326 & 0.0170 & 0.0005 & 0.1056 & 0.0021 \\
$\boldsymbol{L A G}$ & 77.5 & 78.5 & 69.0 & 85.0 & 7.3 \\
$\boldsymbol{V} \boldsymbol{V O} \boldsymbol{T}$ & $32.7 \%$ & $27.5 \%$ & $2.3 \%$ & $88.2 \%$ & $29.3 \%$ \\
\hline
\end{tabular}

PANEL C. Winter Olympic Games (\#8)

\begin{tabular}{lccccc}
\hline & Mean & Median & Minimum & Maximum & SD \\
\hline SIZE & 0.0110 & 0.0024 & 0.0001 & 0.0725 & 0.0022 \\
$\boldsymbol{L A G}$ & 69.1 & 70.5 & 64.0 & 77.0 & 4.5 \\
$\boldsymbol{V O} \boldsymbol{O T}$ & $28.8 \%$ & $20.3 \%$ & $2.8 \%$ & $100.0 \%$ & $32.1 \%$ \\
\hline
\end{tabular}

PANEL D. World Football Cups (\#5)*

\begin{tabular}{cccccc}
\hline & Mean & Median & Minimum & Maximum & $\boldsymbol{S D}$ \\
\hline VOT & $34.7 \%$ & $26.3 \%$ & $4.3 \%$ & $100.0 \%$ & $39.1 \%$ \\
\hline
\end{tabular}

*only 1 included in the cross-sectional regressions and used to compute the statistics in PANEL A.

PANEL E. World Exhibitions (\#10)

\begin{tabular}{lccccc}
\hline & Mean & Median & Minimum & Maximum & SD \\
\hline SIZE (\#1) & 0.0102 & 0.0014 & 0.0000 & 0.0475 & 0.0023 \\
$\boldsymbol{L A G}$ (\#1) & 76.2 & 69.0 & 38.0 & 124.0 & 29.6 \\
$\boldsymbol{V O T}$ (\#6) & $66.9 \%$ & $100.0 \%$ & $2.5 \%$ & $100.0 \%$ & $43.4 \%$ \\
\hline
\end{tabular}

PANEL F. Specialized Exhibitions (\#7)

\begin{tabular}{lccccc}
\hline & Mean & Median & Minimum & Maximum & SD \\
\hline SIZE & 0.0010 & 0.0003 & 0.0000 & 0.0057 & 0.0021 \\
$\boldsymbol{L A G}$ & 49.3 & 47.0 & 13.0 & 88.0 & 27.7 \\
$\boldsymbol{V O T}$ & $100.0 \%$ & $100.0 \%$ & $100.0 \%$ & $100.0 \%$ & $0.0 \%$ \\
\hline
\end{tabular}

